\title{
Programa de investigación-acción sobre Ministerio Público de la Provincia de Buenos Aires. Autonomía de la Defensa; representación del interés público ante conflictos de intereses y defensa de los derechos económicos, sociales, culturales y ambientales ante el Fuero Contencioso Administrativo provincial
}

\author{
Pablo Octavio Cabral ${ }^{1}$ \\ María Cecilia Rita Villegas ${ }^{2}$ \\ Universidad Nacional \\ Guillermo Raúl Moreno ${ }^{3}$ \\ Matías Alejandro Sucunza ${ }^{4}$ \\ Alejandro Medici ${ }^{5}$ \\ de la Plata, Argentina
}

Revista Derechos en Acción ISSN 2525-1678/ e-ISSN 2525-1686

Año 4/N 13 , Primavera 2019 (21 septiembre a 20 diciembre), 635-696

DOl: https://doi.org/10.24215/25251678e350

\footnotetext{
Abogado, especialista en Derecho Administrativo y Administración Pública (UNLP), Director de la Revista Derechos en Acción, integrante del Centro de Investigación en Derecho Crítico de la UNLP. Email: pablooctaviocabral@yahoo.com.ar

2 Abogada, egresada de la Facultad de Ciencias Jurídicas y Sociales de la UNLP, integrante del Ministerio Público de la Nación y del Centro de Investigación en Derecho Crítico de la UNLP.

3 Abogado, adjunto cátedra III de Historia Constitucional, Facultad de Ciencias Jurídicas y Sociales, UNLP. Editor Ejecutivo de la Revista Derechos en Acción, integrante del Centro de Investigación en Derecho Crítico de la UNLP.

4 Abogado (UNLP), especialista en Derecho Procesal Profundizado, especialista en Derecho Administrativo Económico, integrante del Centro de Investigación en Derecho Crítico de la UNLP. Email: sucunzamatias@gmail.com

5 Profesor Titular de Derecho Político en UNLP y UNLPam, Doctor en Derechos Humanos por la Universidad Pablo de Olavide de Sevilla, Investigador categoría I del sistema de incentivos, Miembro del GT CLACSO Pensamiento Jurídico Crítico. Director del Centro de Investigación en Derecho Crítico de la UNLP.
} 
ORCID: https://orcid.org/0000-0001-5768-4958 https://orcid.org/0000-0002-8740-4723 https://orcid.org/0000-0002-6334-659X https://orcid.org/0000-0003-3858-9757 https://orcid.org/0000-0002-9409-8744

Sumario: I. Presentación. II. Equipo de trabajo. III. Metodología.IV. Acciones en el marco del programa.1. Proyecto de Investigación sobre las herramientas para lograr la justiciabilidad de los derechos sociales (ABDA, 2007). 2. Creación de la Secretaría de Protección de Nuevos derechos en la Defensoría General de San Nicolás. 3. Presentación de una propuesta de reforma legislativa al Segundo Encuentro Políticas Públicas para la provincia de Buenos Aires. 4. Presentación del proyecto de ley de reforma de la ley orgánica del Ministerio Público de la provincia de Buenos Aires (Expte. D-1373/13-14).V. Líneas de investigación-acción: 1. Autonomía de la defensa pública. 2. La representación del Interés Público ante conflictos de intereses. 3. La defensa de los Derechos Económicos, Sociales, Culturales y Ambientales (DESCA) en el Fuero Contencioso Administrativo. 4. Políticas de género en el Ministerio Público bonaerense. VI. Fundamentación: 1. Regulación constitucional y legal. 2. Proyectos de reforma de la ley orgánica del Ministerio Público provincial. 3. Suspensión cautelar de la ley 14.442. Sentencia de la SCBA en la Causa I. 72.447 "Procuradora General contra Provincia de Buenos Aires. Inconstitucionalidad ley 14.442". VII. Actividades: 1. Mesa de discusión. 2. Jornada "El Ministerio Público de la Provincia de Buenos Aires".3.Conversatorio. 4. Propuesta legislativa.5.Propuesta de modificación constitucional por enmienda.VIII. Bibliografía.

\section{Presentación}

El presente programa de investigación acción del Centro de Investigación en Derecho Critico -CIDERCRIT- de la Facultad de Ciencias Jurídicas y Sociales de la Universidad Nacional de La Plata, tiene por objeto abordar la problemática del "Ministerio Público de la Provincia de Buenos Aires. Autonomía de 
la defensa; representación del interés público ante conflicto de intereses y defensa de los Derechos Económicos, Sociales y Culturales ante el Fuero Contencioso Administrativo provincial".

Los contornos institucionales del Ministerio Público de la Provincia de Buenos Aires se encuentran desdibujados por una incompatibilidad de su regulación constitucional local con el sistema nacional e internacional de protección de Derechos Humanos, y por la existencia de una incertidumbre respecto del régimen normativo vigente.

La Constitución de la Provincia de Buenos Aires (en adelante, CP) regula la institución en su artículo $189^{6}$, que -a diferencia del art. 120 de la Constitución Nacional (en adelante, CN)- crea un Ministerio Público en cabeza del Procurador y Subprocurador General, sin reconocerle independencia, autonomía funcional ni autarquía financiera.Organismos internacionales de Derechos Humanos observaron que, encontrándose la defensa y acusación penal bajo una misma autoridad, se violentaba la independencia y autonomía de la Defensa Pública afectando garantías del debido proceso adjetivo.

A fin de otorgarle dicha autonomía a la defensa pública, a comienzos del año 2013, la legislatura provincial reemplazó la ley orgánica del Ministerio Público vigente (Ley $\mathrm{N}^{\circ}$ 12.061) sancionando en su reemplazo la Ley $\mathrm{N}^{\circ} 14.442^{7}$. Esta nueva normativa fue impugnada judicialmente por la entonces Procuradora General y suspendida en sus efectos por una medida cautelar dispuesta

\footnotetext{
6 Artículo189.- El Ministerio Público será desempeñado por el Procurador y Subprocurador General de la Suprema Corte de Justicia; por los Fiscales de Cámaras, quienes deberán reunir las condiciones requeridas para ser jueces de las Cámaras de Apelación; por agentes fiscales, asesores de menores y defensores de pobres y ausentes, quienes deberán reunir las condiciones requeridas para ser jueces de primera instancia. El Procurador General ejercerá superintendencia sobre los demás miembros del Ministerio Público.

7 Texto modificado por Ley 14613 que creó el Cuerpo de Magistrados Suplentes y por Ley 14687, que creo Unidades Funcionales de Instrucción y Juicio especializadas en Violencia Institucional.
} 
por la Suprema Corte de Justicia local, la cual se encontró vigente hasta el 29 de mayo de 2019, fecha en que se dictara sentencia definitiva declarando la constitucionalidad de la nueva norma.

Somos consientes que si bien esta decisión judicial viabiliza una norma que intenta hacer compatible la estructura del Ministerio Público con las pautas y principios en los que se fundamenta la autonomía de la defensa, la solución óptima es la modificación del artículo 189 de la CP.

Los siete años de incerteza normativa se agravan por el surgimiento de nuevas problemáticas que exigen reflexiones situadas en la actualidad bonaerense. En primer lugar, la constitucionalización del derecho y la introducción del paradigma de los derechos humanos, supuso una mayor exigibilidad y justiciabilidad de derechos desde un enfoque de derechos. Esto es, la transformación de una visión que los concebía como necesidades, discrecionales y puramente políticas, a un enfoque que los (re)construye como obligaciones jurídicas del Estado, sometido a estándares y mecanismos concretos para su satisfacción.

Ello supone una profundización del rol del Poder Judicial y su intervención en cuestiones que antes eran concebidas como exentas o limitadas al control judicial, exigiendo repensar los alcances y límites de la relación entre funciones estatales en torno al cumplimiento de dichos derechos, la definición del programa de gobierno constitucional y la demarcación de una agenda. Especialmente, porque en las acciones de las autoridades interpretativas, se juega parte importante de la autonomía personal y la realización del autogobierno colectivo.

Todo ello se recrudece cuando sumamos al análisis que, hace más de 20 años, los derechos colectivos han sido reconocidos constitucionalmente. Ello supuso un cambio radical de paradigma en términos de derechos, conflictos y, por ende, en los esquemas de empoderamiento, exigibilidad y justiciabilidad.

De ese modo, los procesos colectivos:

(i) Exigen el desarrollo de toda una estructura (recursos, medios y reglas) que facilite el ejercicio adecuado de los derechos 
involucrados en esa clase de conflictos, totalmente distinta de aquellos individuales que habían eclipsado el entendimiento e interpretación constitucional-convencional hasta entrado el siglo $\mathrm{XX}$; $\mathrm{y}$,

(ii) Suponen una herramienta valiosa y de singular incidencia que generan, en todas las latitudes y en el contexto argentino también, desafíos y problemas múltiples a las estructuras de poder y sus intereses. Entre esas dificultades que los procesos colectivos suponen para la preservación de sus privilegios, podemos mencionar: una ingente cantidad de demandas $\mathrm{y}$ reclamos (exigibilidad de derechos) al Estado, grupos concentrados de poder (v.gr., corporaciones) u otros actores sociales, que motorizan cambios en clave más igualitaria; una amenaza y riesgo real para ciertas conductas, formas y medios indebidos de obtener ventajas o riqueza por parte de ciertos sectores (por ejemplo, cargos administrativos indebidos por sumas individualmente irrisorias); promoción de litigios estructurales vinculados a sujetos de especial prevalencia y/o situaciones de desigualdad histórica, que jaquean el orden de cosas instituido y su legitimación (por caso, la distribución de bienes y servicios, su legalidad y justicia; la asignación presupuestaria en razón de las prioridades constitucionales-convencionales, etc.); un mayor empoderamiento ciudadano, participación y acceso a la información, que favorece y mejora el escrutinio público de las acciones de gobierno y sus razones; el (re)planteo de la organización y distribución del poder y roles en el espacio (público/privado), al incentivar y promover lecturas e intervenciones más equitativas, entre otras.

Cuando aludimos a "estructuras de poder" nos estamos refiriendo a todos aquellos grupos, sectores o personas que tienen una posición de privilegio por resguardar, la cual se halla legitimada por cierto tipo de interpretación jurídica y respecto de las cuales la exigibilidad y justiciabilidad de derechos en clave igualitaria supone una amenaza. Hablamos de las corporaciones económicas, de grupos empresarios, de gremios y sindicatos, la Iglesia y/o el Estado. Es decir, los actores hegemónicos del 
sector público y privado que monopolizan o detentan el poder real en términos de fuerza pública, regulación económica, social y/o política. Ellos son quienes, en principio, más se favorecen de la inexistencia de un sistema de procesamiento colectivo adecuado.

Los procesos colectivos tienen una incidencia gravitante en la definición de las políticas públicas. Esta circunstancia incomoda a los poderes naturalmente políticos, pues los pone de cara a problemas que no quieren abordar de forma estructural; porque condiciona la actual forma de gestionar o administrar (focalizada y mayormente asistencial), la cual les brinda otros beneficios, control social y prebendas; porque limita el uso discrecional de fondos y el manejo presupuestario y aumenta la rendición de cuentas y responsabilidades; o, porque rompen con la lógica del caso a caso individual que, en la administración del problema estructural, no sólo le es más económica al Estado sino que pospone o suspende dificultades más relevantes en términos de discusiones reales acerca de la distribución del dinero público en función de los valores constitucionalmente prevalentes. En esta esfera, la actuación que pueda desenvolver el Ministerio Público es fundamental y crítica.

En segundo lugar, también se han acrecentado los conflictos de intereses, especialmente en razón de la mayor complejidad en las relaciones, vinculaciones público-privado y en el entramado institucional-corporativo, circunstancia que obliga a crear instancias y medios para su fiscalización y el debido resguardo del interés general. Por ejemplo, a través de la intervención del Ministerio Público.

En tercer término, el reconocimiento de los DESCA hace necesario incorporar a la estructura del Ministerio Público provincial defensorías especializadas en la temática para intervenir en cualquier fuero donde se dispute su exigibilidad y, especial y particularmente, ante el Fuero Contencioso Administrativo bonaerense.

Finalmente, la visibilización de los reclamos contra estructuras patriarcales en defensa de la igualdad de la mujer y otros 
colectivos en situación de vulnerabilidad, imponen una visión del organismo que internalice la perspectiva de género en tanto exigencia constitucional-convencional y la traduzca en una agenda institucional y de litigio en consonancia con las imposiciones jurídicas de los sistemas de protección regional y universal de derechos humanos.

Las actividades se desarrollarán en los siguientes ejes temáticos:

1. Autonomía de la defensa pública.

2. Representación del interés público ante conflictos de intereses.

3. Defensa de Derechos Sociales ante el Fuero Contencioso Administrativo.

4. Políticas de género en el Ministerio Público bonaerense.

\section{Equipo de trabajo}

Director: Prof. Pablo Octavio Cabral

Codirector: Dr. Alejandro Medici.

Coordinador: Prof. Guillermo Raúl Moreno

Grupo Promotor: Fueron invitados: Mario Coriolano (Defensoría de Casación de la Provincia de Buenos Aires), Luis Arias (Justicia Contencioso Administrativa), Marcelo Schreginger (Justicia Contencioso Administrativa), Fernando Maitini (CIDerCrit), Pablo Giurleo (CIDerCrit), José Ignacio López (Justicia Federal), Cecilia Villegas(Ministerio Público Fiscal de la Nación), Gabriel Ganon (Ex titular de la Defensoría General de Santa Fe), Homero Bibiloni (CIDerCrit) Julián Axat (Programa ATAJO, Ministerio Público Fiscal de la Nación), Anibal Hnatiuk (Defensoría de Casación de la Provincia de Buenos Aires), Luciano Savignano (Justicia Contencioso Administrativa), Irina Leal (Profesora de Derecho Administrativo UNLP), Víctor Violini (Justicia de Casación Penal), Matías Sucunza (Justicia de la Provincia de Buenos Aires), Mauro Benente (Instituto Interdisciplinario de Estudios Constitucionales de la Universidad de José 
C. Paz.), Daniel Pérez Guillén (Judiciales bonaerenses y CTA) y Carlos Raimundi (CIDerCrit).

\section{Metodología}

\section{Introducción}

La presente propuesta de investigación-acción, se interroga sobre las necesarias reformas organizacionales que deben modelarse en un tiempo de crisis, donde debemos encontrar las fuerzas sociales y las funciones institucionales para resolver los profundos desarreglos estructurales existentes.

En la historia reciente argentina, desde las últimas enmiendas constitucionales federal y bonaerense de 1994 y bajo la incidencia de coyunturas sociales críticas, diversas voces se han pronunciado acerca de la necesidad de amplias reformas institucionales en ámbitos relevantes vinculados directamente a la misión de nuestro Centro de Investigación: los obstáculos económicos, sociales y culturales para el ejercicio de los Derechos Humanos; el acceso a la justicia; el funcionamiento de servicios de procuración y defensa pública; la perspectiva de género; la participación de las ciudadanías titulares de la reforma constitucional; y, los marcos normativos de todos estos aspectos de la relación entre instituciones y sociedad.

En ese marco, emerge la necesidad de reformar las constituciones federal y bonaerense. Así, a título meramente ejemplificativo, podemos señalar:

a) La propuesta de una constituyente social por parte de la Central de Trabajadores Argentinos desde fines de los 90 y durante la crisis social de 2001/2002.

b) El más reciente Foro por una Nueva Constitución.

c) Las propuestas de reforma al poder judicial federal y/o provincial en razón de las objeciones vinculadas a su estructuración, funcionamiento y legitimidad. Particularmente, en función de las preocupaciones que genera su obsolescencia como dispositivo para abordar la conflictividad, su concepción de poder, 
el modelo de gestión y las prácticas que ha construido. Quizás la más simbólica del último tiempo haya sido el "Lawfare". Esto es, la articulación de operaciones de inteligencia a través de estructuras de poder estatal, económico, informal o mediático, tendientes al armado de causas y la instalación en el imaginario social de una postverdad, socavando las garantías básicas del debido proceso, el derecho de defensa en juicio y las garantías de imparcialidad de jueces y fiscales.

d) La necesaria adecuación en el ámbito bonaerense de la institución del Ministerio Público a un paradigma de Derechos Humanos, adecuación que constituye una exigencia del bloque de constitucionalidad y convencionalidad. En esos términos, no constituye una potestad discrecional sino una obligación jurídica del Estado argentino plenamente exigibile y justiciable en todos sus niveles e instancias, la cual supone el deber detransformar al MP en un órgano autónomo que separe funcional y financieramente los servicios públicos de procuración y defensa, asegurando en el proceso penal la paridad de armas de acuerdo a un esquema de tipo acusatorio oral; que cumpla con todas las funciones no penales de los servicios de procuración y defensa pública para representar los intereses públicos de la sociedad, garantizando el acceso a la justicia y tutela diferenciada de los DESCA y del interés público ante el fuero contencioso administrativo bonaerense. Especialmente, teniendo en mira las necesidades de los grupos desaventajados.

Desde distintos ámbitos sociales e institucionales se ha propuesto que estas reformas se plasmen en un nuevo marco de convivencia federal y, en lo que en términos de situación y proximidad nos incumbe, bonaerense.

Estas iniciativas deben comprenderse en un marco histórico paradojal, que muestra, de un lado, grandes innovaciones en el derecho constitucional regional, vinculadas a la participación democrática, el pluralismo cultural, los derechos humanos en general, pero especialmente en los DESCA (Derechos Económicos, Sociales, Culturales y Ambientales), pero al mismo tiempo, un agravamiento de las desigualdades socioeconómicas, 
culturales, ambientales producto de la persistencia de políticas neoliberales que erosionan las bases del estado democrático y social.

En especial en Argentina, hemos vuelto a recaer en una crisis socioeconómica producto de la implementación de dichas políticas ideológicamente sesgadas hacia un modelo excluyente y sus temibles consecuencias desestructuradoras de la vida cotidiana de personas, familias, grupos y redes sociales.

\section{Fundamentación}

La democracia argentina, como las de la región, fueron consideradas a partir de la salida de regímenes militares o de regímenes donde no existía la posibilidad de la competencia electoral pluralista (ej. México o Colombia), como regímenes de "transición".

Sin embargo, una vez que estos regímenes políticos se consolidaron, se buscó adjetivar las democracias "realmente existentes" para dar cuenta de sus peculiaridades. Aparecen miles de páginas sobre estas democracias y sus adjetivaciones, las cuales ya no pueden considerarse "en transición". Incluso, se constatan innovaciones importantes en el campo semántico de la teoría política y constitucional: "poliarquías", "democraduras", "democracias débiles", "defectivas", "delegativas", "populismos", sea de tipo "conservador" o "progresivo".

Al mismo tiempo, la doctrina del derecho constitucional y público en general, discurre por caminos relacionados que buscan la explicación de esas peculiaridades en el contraste con modelos prescriptivos de democracia o esquemas funcionales de ingeniería constitucional de los poderes del estado. Por ej., "democracia deliberativa" vs. "hiperpresidencialismo", modelos presidencialistas, semipresidencialistas, parlamentarios, funcionamiento del poder judicial, su independencia o la naturaleza del control de constitucionalidad.

Normalmente, en forma paralela, discurre el análisis de los Derechos Humanos a partir del bloque de constitucionalidad, el 
diálogo y convergencia de fuentes y las obligaciones del Estado. Predomina una mirada casuista, jurisprudencial y que se centra en derechos específicos o a veces de forma más general, en categorías de derechos.

Por supuesto que estos estudios e investigaciones son fundamentales, no sólo como marcos analíticos sino como herramientas prácticas para dar cuenta de la importancia de constitucionalizar transversalmente todas las ramas del derecho desde un paradigma centrado en los derechos. También sirven para recuperar la relevancia de recurrir a la experiencia que provee el análisis comparado en el funcionamiento de las instituciones y poderes del Estado en su estrecha vinculación con las variables que hacen a la calidad de la democracia.

Sin renunciar a este marco general, ni a la posibilidad de encarar renovados esfuerzos de investigación en estas áreas, el Centro de Investigación en Derecho Crítico, así como otros ámbitos sociales e institucionales de nuestra Universidad y Facultad como del ámbito social que pretendemos asociar a experiencias de investigación/acción, procuran un plus que complementa el tratamiento usual de estos problemas, tanto desde el abordaje de los problemas e interrogantes que hacen a este campo semántico político institucional como desde la metodología de investigación.

Las dimensiones fundamentales que aportan las metodologías de Investigación/acción y los programas inspirados en ellas, son las de la participación ciudadana y la experiencia de los actores sociales e institucionales vinculados a los objetivos de transformación social e institucional. Estos aportes amplían la idea de democracia formal normalizada, la cual se limita a analizar lascondiciones institucionales y político electorales, sin relacionarla con las condiciones sociales del ejercicio de la ciudadanía. Esto es, con la justicia social.

En efecto, después de que se generalizara la literatura politológica y constitucional acerca de la denominada "tercera ola de democratización", las "transiciones", "ingenierías constitucionales" y las adjetivaciones de las democracias "realmente 
existentes", generalmente han omitido reflexionar sobre el poder constituyente a partir del protagonismo popular o, por lo menos, problematizar las relaciones entre este retaceo y la (in) justicia social.

Pensando desde nuestra nación y región -que es la más desigual del planeta-, esta omisión induce a la sospecha. Sospecha que, como sabemos, es la base de la actitud crítica en la vida y también en la investigación, extensión y docencia. La actitud crítica no renuncia a la generalización del conocimiento, ni a su objetividad. Pero los construye desde bases más sólidas al hacer visible lo opaco, al reflexionar sobre los fines de la investigación. Toda investigación no es sólo por el conocimiento mismo, sino para alguien y para algo.

Desde esta mirada crítica, la omisión de la pregunta por la participación en el pensamiento, problematización y reformas a los marcos institucionales de nuestros derechos y de nuestra convivencia; por las causas históricas y estructurales de su retaceo; por la relación entre este retaceo y la ineficacia relativa de todos los derechos humanos constitucionalmente declarados y reconocidos; por la relación entre esos condicionamientos y la (in)justicia social; la carencia de relativa autonomía para orientar las políticas económicas o sociales; o, incluso, la imposibilidad de plantear la pregunta básica en una democracia constitucional acerca de qué marcos institucionales tenemos y cuáles deberíamos tener, no es un dato menor.

Se trata de volver a vincular el derecho con las ciudadanías. De salir del encierro que nos plantean el claustro y el texto, para entender el derecho y los derechos en acción y abrir los estatutos normativos de las instituciones a una hermenéutica social que las piensa-problematiza en su funcionamiento, desde las interpelaciones y necesidades sociales.

Esto es, poner en crisis la (hiper) especialización del lenguaje jurídico y su monopolio por parte de los especialistas, circunstancia que deriva (y se reconstituye) en la expropiación del conflicto de sus titulares, la burocratización sesgada de su 
abordaje, la despersonalización de la composición del mismo y el debilitamiento del protagonismo de las ciudadanías en la vida de las instituciones.

Si las Constituciones y el derecho en general, en vez de conformar un lenguaje común, popular, accesible y disponible, aparecen como un código encriptado, opaco y elitista, devienen menos garantistas y democráticas. Un instrumento de opresión, preservación de privilegios y exclusión y no de mayor autonomía personal, autogobierno colectivo e igualdad.

Los poderes fácticos (in)nominados constitucionalmente (Bartolomé Clavero,2007) o neoabsolutistas (Luigi Ferrajoli, 1997,2000 y 2011), tanto públicos como privados, transnacionales o nacionales, se benefician de la lejanía cultural de las instituciones, del mantenimiento de desarreglos políticos $\mathrm{y}$ económicos profundos en nuestro diseño constitucional,de la opacidad del derecho y de la hermenéutica que a partir del mismo construyen las autoridades interpretativas para la preservación de sus intereses hegemónicos, encontrando un marco para poder apropiar o resignificar los bienes sociales que son condición y contenido de los derechos constitucionales en una sociedad democrática con pretensión de justicia.

Para la perspectiva crítica por la que bregamos, la participación ciudadana resulta variable fundamental de la autonomía personal y democracia. Está íntimamente vinculado con el carácter democrático y social de nuestros regímenes políticos y constitucionales. Con el grado de igualdad social, institucional y jurídica de los derechos humanos. Con la calidad y pluralismo de la ciudadanía.

Por lo tanto, proponemos un programa de investigaciónacción participativa que, articulando tareas de investigación, extensión y docencia, fomente una cultura jurídica crítica o el avance de una "conciencia jurídica social" (Sampay, 1973). Pretendemos que esa resignificación epistémica permita la construcción de un diálogo horizontal e igualitarioentre los operadores jurídicos (v.gr., las y los docentes, graduados y estudiantes de 
derecho; magistradas y agentes con experiencia en el ejercicio de la justicia; la procuración; o, abogacía pública-privada), las restantes disciplinas vinculadas con la conflictividad, la ciudadanía en general y los distintos actores de la sociedad civil.

\section{Objetivos}

Generales:

a) Promover procesos participativos que aporten a la discusión sobre nuevos marcos institucionales en el ámbito federal y bonaerense ycontribuyan a la construcción de solucionesa la crisis social,maximizando los derechos de las ciudadanías.

b) Visibilizar, comprender y (de)construir las condiciones que se requieren para garantizar dichas transformaciones institucionales en la sociedad argentina y bonaerense del siglo XXI.

c) Promover una cultura ciudadana plural, participativa, protagónica y responsable en términos de derechos e instituciones.

d) Fomentar que se acepte como un presupuesto esencial de la sociedad democrática en la que vivimos, la discusión y participación permanentes acerca de la institucionalidad que tenemos y la que deberíamos tener.

e) Impulsar la conciencia jurídica social, recuperando al derecho como una herramienta para la emancipación igualitaria y desencriptando las prácticas e instituciones jurídicas que hacen a las ciudadanías y el ejercicio cotidiano de sus derechos constitucionales.

Especificos:

a) Promover espacios de discusión entre organizaciones sociales-instituciones-referentes- sobre los marcos institucionales en materia de justicia federal y provincial, en especial los servicios de justicia, procuración y defensa.

b) Impulsar estrategias y líneas de intervención para el abordaje de la conflictividad desde una perspectiva integral e 
integrada, que recupere al conflicto como noción estructurante y a la persona-colectivo como titular del mismo.

c) Generar espacios para repensar el acceso a la justicia individual y colectivo, propiciando medidas que permitan robustecer su condición de garantías fundamentales desde un enfoque de derechos.

d) Propiciar proyectos legislativos y/o reglamentarios para regular adecuadamente el debido proceso colectivo en el orden federal y provincial.

e) Articular líneas de investigación y mesas de diálogo para pensar en torno a las tensiones que los conflictos y procesos colectivos pueden presentar en el esquema federal de competencias y como herramientas de empoderamiento, participación, control, rendición de cuentas y cambio (estructural) en relación a conductas lesivas de agentes públicos o privados y/o exigibilidad de intereses, en especial, de aquellos asociados a la planificación, ejecución, monitoreo y evaluación de "políticas públicas" desde un enfoque de derechos.

f) Apoyar instancias para discutir y trabajar en torno a la legitimidad y responsabilidad de las funciones institucionales en general y de la justicia en particularante la ciudadanía,propiciando mecanismos que robustezcan su participación y rendición de cuentas.

g) Promover la discusión, consenso y propuestas específicas de reformas institucionales a nivel constitucional y legal de los servicios y funciones de justicia, procuración y defensa.

h) Promover este debate en general, como en aspectos parciales que hacen tanto a la garantía de los derechos, como la calidad del funcionamiento de las instituciones políticas, las políticas públicas y los modelos de funcionamiento de los poderes del Estado en sus diversos niveles, la legislación, la administración y el poder judicial.

i) Observar y comparar los procesos constituyentes en nuestra región y en la esfera internacional, recuperando experiencias y aprendizajes de cara a los proyectos de reformas que se promuevan. 
j) Analizar, clasificar, comprender y proponer estándares y acciones que integran contemporáneamente procesos constituyentes democráticos participativos desde la calidad de la presencia ciudadana en deliberación y protagonismo.

k) Identificar y problematizar los obstáculos culturales, fácticos, económicos y sociales a la posibilidad de la participación y debate sobre este tópico, considerando especialmente los desarreglos estructurales existentes, la diversidad de actores y sus intereses, el hecho del pluralismo y la complejidad de escenario político-jurídico actual.

1) Promover el empoderamiento y la participación de grupos sociales estructuralmente desaventajados, respecto de los cuales los obstáculos señalados se agravan exponencial y tranversalmente. Entre ellos, mujeres, pueblos originarios, inmigrantes, niñez y adolescencia, agricultura familiar, y, organizaciones cooperativas y de la economía popular.

11) Generar espacios, mesas e instancias de discusión en torno a la exigibilidad y justiciabilidad de los DESCA, recuperando su condición de obligaciones jurídicas exigibles. En particular, enfatizar en cada una de las actividades y medidas a realizar, la importancia del enfoque de derechos, estándares e indicadores como mecanismos para mejorar dichas acciones, la inexistencia de generaciones o jerarquías de derechos, su indivisibilidad e interdependencia y la necesidad de transformar el rol del Ministerio Público, el trabajo de los abogados y la justicia en su abordaje y procesamiento.

m) Participar en asociación con instituciones y organizaciones de la sociedad civil en foros, plataformas, campañas de difusión y concientización acerca del constitucionalismo democrático-social, los derechos constitucionales y la relevancia de la transformación constitucional.

n) Promover, organizar, colaborar y participar en actividades académicas teórico-prácticas curriculares y extracurriculares sobre estos tópicos. 
ñ) Promover, organizar, articular en forma sinérgica proyectos de investigación, extensión y transferencia docente de grado y posgrado sobre los tópicos señalados.

\section{Metodología}

La IAP desarticula el dualismo propio de las ciencias llamadas "duras", entre sujeto y objeto de investigación. Propone articular, reflexivamente, a los sujetos investigadores con los sujetos investigados desde un fin transformador del campo de intervención. Su metodología se caracteriza por buscar producir conocimiento para lograr fines de transformación o cambio social e institucional.

En el caso de la investigación acción sobre constitucionalismo democrático y social -y más específicamente su dimensión instituyente-, es la voluntad de ciudadanía activa y protagónica para incidir en las instituciones y su relación con la sociedad el eje articulador entre investigadores (docentes, graduados y estudiantes) y ciudadanía participante.

Ambos sujetos comparten reflexivamente el fomento de una cultura jurídica y democrática social crítica, que apropie como un valor positivo la normalidad de la participación y deliberación protagónica acerca de las instituciones y los derechos. Empezando por su código inicial, básico y nuclear que es de nivel constitucional, o sintéticamente, la Constitución.

También la metodología propuesta tiende a disolver el dualismo entre teoría y práctica, al fomentar una relación transversal entre investigadores y extensionistas; ciudadanía formada jurídicamente y ciudadanía lega; academia e instituciones y organizaciones de la sociedad civil que asumen el carácter, fundamental y normal al mismo tiempo, de la participación popular en materia constitucional y constituyente (Fals Borda, 2013).

Ello se materializa en el tipo de vínculo que se construye entre sujetos y las formas que asume. Entre otras, el consenso de un programa de acciones que supone generar espacios de 
diálogo y participación, conocimiento compartido, núcleos formativos que puedan multiplicarse y ampliarse a nuevos actores sociales e institucionales ${ }^{8}$.

De ese modo, la articulación entre metodología IAP y los objetivos generales y específicos de la propuesta, se evidencian al pensar en que la discusión institucional lejos de quedar reservada al ámbito académico debe ser un proceso protagonizado por las ciudadanías en sus plurales expresiones, las organizaciones de la sociedad civil, los actores sociales relevantes por sus funciones (juezas, fiscales, defensoras, legisladores y operadores jurídicos en general) y las organizaciones populares.

Para ello se propone la formación de núcleos promotores o, más específicamente, Grupos de Investigación Acción Participativas (G.I.A.P), (RodriguezVillasante, 2000). que articulen a personas, grupos y representaciones institucionales que compartan la necesidad, interés y posibilidad de impulsar y materializar las reformas institucionales propuestas. Todo ello con el fin de modificar o cambiar aspectos de las relaciones entre instituciones y sociedades. El conocimiento así generado vale en tanto se orienta a plasmar una propuesta y una práctica de la transformación que se busca ${ }^{9}$.

Esta conformación de grupos dinamizadores orientada a formar redes entre sociedad e instituciones, se complementa con la propuesta de proyectos acreditados de investigación y extensión, que sean el reverso burocrático formalhacia la UNLP de las acciones de transformación que se proponen hacia el ámbito contextual institucional y social.

8 Medici, A. (2018), Articulación de docencia-investigación extensión para una práctica pedagógica crítica en la enseñanza de los Derechos Humanos, Derechos En Acción, 7(7). https://doi.org/10.24215/25251678e147.

9 Sagastizabal, María Ángeles y Perlo, Claudia (2002),La investigación-acción como estrategia de cambio de las organizaciones, Editorial Stella-La Crujía. 
Esta doble vía requiere entonces articular los siguientes aspectos de investigación-acción:

a) Estado de la cuestión y construcción de un acervo común, el cual se renueva permanentemente.

b) Promoción del tema a nivel de la facultad y universidad para articular la participación de docentes, investigadoras y extensionistas de todos los claustros. Reuniones, conferencias, jornadas, congresos, seminarios de grado y posgrado.

c) Mapeo discursivo de las tomas de posición de un conjunto suficientemente representativo de instituciones, organizaciones políticas, de la sociedad civil, la cultura, regionales, pueblos originarios, inmigrantes y de género sobre los temas de agenda. Los mismos se ponderarán según su capacidadde incidencia en la agenda pública vinculada, escrutándose los argumentos que abastecen su posicionamiento.

d) Formación de grupos de discusión focalizados en diversos sectores para confirmar y complejizar el mapeo anterior.

e) Entrevistas en profundidad a especialistas, líderes ciudadanos, funcionarias, legisladoras $\mathrm{u}$ otros actores de la sociedad civil.

f) Formulación de un diagnóstico.

g) Formulación de un Programa de IAP que incluya:

(i) Realización de conferencias, seminarios y participación en foros, plataformas y campañas de concientización ciudadana que sean transversales y vinculen el ámbito académico, institucional y de organizaciones de la sociedad civil.

(ii) Realización de proyectos de investigación y de extensión relacionados con diversas problemáticas constitucionales asociadas con lo instituyente en materia de poderes y derechos humanos, participación ciudadana en torno a la pregunta sobre qué Constitución tenemos y cuál deberíamos tener.

(iii) Actividades consultivas y propositivas de incidencia, acerca de políticas públicas con enfoque de derechos, legislación y modelos de reforma y organización institucional. 
(iv) Devolución periódica de todo lo actuado a las organizaciones e instituciones participantes, como forma de generar reflexividad, autoevaluación participativa y sinergias en tono a los temas y problemáticas abordadas.

Como señalamos con anterioridad, los programas que articulan investigación y extensión desde la IAP no se limitan a buscar el conocimiento per se. Por eso pueden o no finalizar con los informes o conclusiones que exige el ámbito burocrático de la administración académica.

Tampoco se reducen a los tiempos formales de ejecución de los proyectos de investigación y/o extensión, sino que -pudiendo conciliarse con esos formatos y tiempos, presentando conclusiones tentativas, preliminares o abiertas a los efectos de la validación burocrática-fomentan una espiral reflexivo que intenta transformar el campo práctico en el que intervienen y centrar el protagonismo en la participación activa de los actores sociales, los cuales tienen sus propios tiempos y formas.

Por eso mismo, los formatos de comunicación de los procesos de IAP no se reducen a los usuales en el ámbito académico, aunque tampoco los descartan:

a) Publicaciones en revistas especializadas (por ejemplo, ReDeA, REDHES, Crítica Jurídica, Anales, Revista de Estudios Sociales y/o EL Otro Derecho).

b) Publicaciones de divulgación que reflejen los procesos de participación y las propuestas ciudadanas.

c) Participación en espacios de radio y tv de la UNLP y otros para difundir el proceso de IAP.

d) Formación de blogs, páginas web y redes sociales del proyecto, en red con las organizaciones e instituciones participantes, que reflejen el estado de las acciones, conclusiones y propuestas parciales, difundiendo los acontecimientos vinculados al programa, su campo de intervención, problemas y temas. 


\section{Acciones en el marco del programa}

En primer lugar se recuperan las siguientes experiencias:

\section{Proyecto de Investigación sobre las herramientas para lograr la justiciabilidad de los derechos sociales (ABDA, 2007)}

En el marco de la Asociación Bonaerense de Derecho Administrativo se desarrolló un proyecto de investigación sobre las herramientas para lograr la justiciabilidad de los derechos sociales. El equipo de trabajo, integrado por Pablo Octavio Cabral, Pablo Giurleo, Karen Bentancur, Marcelo Schreginger, Guillermo Moreno, Juan Azcune, entre otros, desarrolló un relevamiento de la jurisprudencia del nuevo fuero contencioso administrativo en la materia, rescatando aquellas experiencias exitosas y analizando las vías procesales más aptas para la mentada judicialización.

Respecto de la cuestión en estudio, se destacaba en aquel proyecto de investigación que una de las problemáticas consistía en la "inexistencia de un órgano estatal especializado en Derecho Público, que realice la defensa de los ciudadanos que reclaman la protección de sus derechos sociales, en el nuevo fuero contencioso administrativo", para lo cual se trazó como objetivo "realizar un análisis del sistema de defensa oficial en casos de afectación de derechos sociales y proponer la reestructuración del Ministerio Público, a fin de permitir el acceso a la Justicia a los ciudadanos afectados"10.

Como producto de dicho proyecto, que se extendió durante los años 2007/2008, se desarrollaron jornadas, reuniones y se presentaron ponencias en congresos con algunas de las ideas discutidas en el grupo de trabajo.

\footnotetext{
10 Proyecto de Investigación sobre las herramientas para lograr la justiciabilidad de los

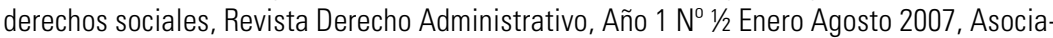
ción Bonaerense de Derecho Administrativo, La Plata, 2007, págs.. 29/39.
} 
Entre las actividades realizadas destacamos:

a) Encuentro: Acceso a la justicia en casos de violaciones a derechos sociales. 22 de Octubre de 2007,Auditorio "Emilio Mignone", CELS.

b) Presentación titulada "El proyecto de Investigación sobre la Efectividad de los DESC en el Fuero Contencioso Administrativo", en las Primeras Jornadas sobre Derecho y Vulnerabilidad Social, organizado por la Asociación Bonaerense de Derecho Administrativo (ABDA), el Centro de Estudios Interdisciplinarios (CEI) y el Centro de Estudios Legales y Sociales (CELS), realizadas los días 18 y 19 de octubre de 2007 en la ciudad de La Plata.

Entre las producciones más relevantes, podemos mencionar:

a) Bentancur, Karen"11, ponencia "El rol de las defensorías públicas en defensa de los DESC".

b) Urbina, Natalia y Azcune, Juan I (2007), ponencia " $L a$ necesaria creación de las defensorías especializadas para actuar ante el Fuero Contencioso Administrativo", presentada en $1^{\circ}$ Congreso Provincial de Ciencias Jurídicas, "El Ejercicio de la Abogacía: Nuevos Paradigmas.El Rol de Los Colegios de Abogados en la Capacitación Permanente" (La Plata, 13 y 14 de Septiembre de 2007).

c) Savignano, Luciano C. (2007), ponencia "El Ministerio Público Fiscal de la Provincia de Buenos Aires ante el Fuero Contencioso Administrativo y de Ejecuciones Tributarias. Una propuesta", presentada en el IV Congreso de la Asociación Bonaerense de Derecho Administrativo (ABDA). Homenaje al profesor Agustín Gordillo. Dolores, 23 y 24 de Noviembre de 2007 y publicada en Revista RAP Bs. As. (73/74), pág. 163 y siguientes.

d) Cabral, Pablo O. (2007), ponencia "Las Funciones Sociales de la Justicia en lo Contencioso Administrativo", en las 2das.

\footnotetext{
11 Karen Bentancur se desempeñaba como Defensora Oficial y Asesora de Menores Depto. Judicial Zárate - Campana.
} 
Jornadas de Derecho Administrativo de la Ciudad Autónoma de Buenos Aires, realizadas los días 20 y 21 de septiembre de 2007.

e) Azcune, Juan I (2010), trabajo "La necesaria reformulación del Ministerio Público de la defensa para actuar ante la Justicia Administrativa como garantía de los Derechos Económicos, Sociales y Culturales en la Provincia de Buenos Aires".

f) Cabral, Pablo O. (2008), ponencia "La exigibilidad de los Derechos Económicos Sociales y Culturales en la Justicia Administrativa", en las XIX Jornadas Bonaerenses de Jóvenes Abogados organizadas por el Colegio de Abogados de San Nicolás, desarrolladas en la ciudad de San Nicolás de los Arroyos los días 3 y 4 de octubre de 2008.

g) Cabral, Pablo. O. (2008), "El poder judicial como berramienta institucional de participación ciudadana en el marco de la teoría de la democracia deliberativa", publicado en la Revista de la Asociación de Derecho Administrativo de la Ciudad Autónoma de Buenos Aires en el mes de septiembre de 2008 -año 2, N 2-, pág. 157 a 185 (disponible en SEDICI; http:// sedici.unlp.edu.ar/handle/10915/69752).

h) Cabral, P. O. (2008), "La pretensión prestacional en el proceso contencioso Administrativo Bonaerense", en "Derecho Público para Administrativistas", dirigido por el Dr. Jorge Luís Bastons,LibreríaEditora Platense, La Plata, 2008, pág. 741-766 (disponible en SEDICI; http://sedici.unlp.edu.ar/ handle/10915/70128).

\section{Creación de la Secretaría de Protección de Nuevos derechos en la Defensoría General de San Nicolás}

En el marco de las actividades de difusión en la región norte de la provincia de Buenos Aires, se desarrollaron cursos de capacitación en proceso contencioso administrativo para defensorías del Ministerio Público provincial. Allí participaron integrantes de diversos departamentos judiciales y, a propuesta del Defensor General del Departamento Judicial de San Nicolás, 
Dr. Gabriel Ganon, se estableció una prueba piloto consistente en la creación de una defensoría especializada en derechos sociales para actuar, entre otros, ante el Fuero Contencioso Administrativo.

El Defensor General de San Nicolás resolvió "crear la Secretaría de Protección de Nuevos Derechos, con competencia para actuar en el fuero Civil, Comercial, de Familia y Contencioso Administrativo, dejando dispuesto que si el aumento de litigiosidad lo indica se creará una Defensoría para tales derechos"

En los considerandos de la resolución del Defensor General de San Nicolás se puede leer que: "la labor de los Defensores Oficiales requiere de una habilitación legal de competencia, que conlleve una asignación de estructura y medios para poder enfrentar los retos de litigar en un proceso dónde el desequilibrio económico y de poder de las partes, inclina la balanza en favor de los administradores de la cosa pública. También es necesario, además de otorgar la competencia formal para actuar en el fuero contencioso administrativo, capacitar al personal y a los Defensores Oficiales en la materia administrativa a fin de equiparar su nivel profesional con el de los Abogados del Estado que, como vimos, se encuentran especializados en la materia. En este sentido, y dentro de la batería de medidas que desde esta Defensoría General se impulsarán a tal efecto, ordenaré la capacitación de todo el personal letrado del organismo, a través de los cursos gratuitos a distancia que brinda el Instituto Interamericano de Derechos Humanos".

Argumentó también que "Si bien actualmente de las Secretarías Generales dependientes de esta Defensoría General -Civil y Penal- no se han reflejado en sus estadísticas, tal como surge de sus respectivas resoluciones registradas, derivaciones de conflictos atinentes a esta materia, resulta que desde la Procuración General de la provincia no se ha incluido dentro de los fueros de intervención a la justicia administrativa. No obstante ello y a fin de garantizar mínimamente -estas Unidades de Defensa no

12 Resolución del 11/10/2007. 
se encuentran especializadas- los derechos sociales, económicos y culturales de los afectados, esta Defensoría Oficial ha iniciado acciones en el fuero mencionado en reclamo de prestaciones atinentes a la salud, resultando su accionar insuficiente para realizar una adecuada intervención debido a que estos derechos de tercera generación poseen distinto marco de actuación para poder ser efectivizados".

A partir de la formalización de dicha estructura especializada, la Defensoría inició diversos procesos contencioso administrativos en reclamo de derechos económicos, sociales y culturales.

La experiencia piloto fue expuesta en la ciudad de Montevideo (Uruguay), en el Seminariosobre "Las Defensorías Sociales en el Acceso a la Justicia”, realizado del 9 al 11 de diciembre de 2009 y organizado por el Centro de Formación de la Cooperación Española en Montevideo y la Unión Iberoamericana de Colegios y Agrupaciones de Abogados ${ }^{13}$.

También se presentó en San Nicolás mediante el dictado del "Curso de Capacitación para Agentes del Ministerio Público de la Defensa en materia contencioso administrativa" del Departamento Judicial de San Nicolás, llevado a cabo los días 18 y 25 de marzo y 1 y 8 de abril de 2008. El mismo fue organizado por la Defensoría General del Departamento Judicial de San Nicolás y la Procuración General de la Suprema Corte de Justicia de la Provincia de Buenos Aires.

Dicho curso se replicó en otras ciudades de la región. Por ejemplo, durante los meses de mayo y septiembre de 2009, se llevó adelante en Pergamino la Capacitación sobre "Derecho Administrativo y Protección de los Derechos Fundamentales (en materia contencioso-administrativa)", actividad que fue organizada por la Procuración General de la Suprema Corte de Justicia de la Provincia de Buenos Aires.

13 Exposición a cargo de Pablo Cabral y Gabriel Ganon titulada "La justiciabilidad de los DESC ante el Fuero Contencioso Administrativo bonaerense y el papel de la defensoría pública". 
Por último,es relevante destacar que la experiencia se llevó nuevamente a la Universidad de la República de Montevideo (Uruguay) y se replicó en la Universidad de La Habana (Cuba).

En Uruguay, a través de la conferencia titulada "La experiencia de judicialización de derechos sociales en la justicia administrativa de la Provincia de Buenos Aires y de la Ciudad Autónoma de Buenos Aires" en la "Jornada sobre la judicialización de los derechos sociales en Uruguay, Argentina y Cuba", realizada en la Sala del Consejo, organizada por el Instituto de Derechos Humanos y el Consultorio Jurídico de la Facultad, con el auspicio de la Sede Suramericana del Instituto Interamericano de Derechos Humanos, Montevideo, diciembre de 2013.

En Cuba, durante las Jornadas sobre la judicialización de los derechos sociales en Uruguay, Argentina y Cuba, organizadas por la Universidad de La República, Universidad Nacional de La Plata y la Universidad de La Habana, Cuba, los días 17 a 19 diciembre de 2014.

\section{Presentación de una propuesta de reforma legislativa al Segundo Encuentro Políticas Públicas para la provincia de Buenos Aires}

Desde la Asociación Abogados por la Justicia Social, se presentó el proyecto "Defensorías públicas ante el Fuero Contencioso Administrativo. Propuesta de creación de la Defensoría Pública para litigar ante el Fuero Contencioso Administrativo bonaerense", en el Segundo encuentro de políticas públicas para la Provincia de Buenos Aires, La Matanza, 2013.

\section{Presentación del proyecto de ley de reforma de la ley orgánica del Ministerio Público de la provincia de Buenos Aires (Expte. D-1373/13-14)}

En el año 2013 el Diputado Marcelo Saín, tomando la iniciativa presentada por la Asociación Abogados por la Justicia Social, presentó en la legislatura provincial un proyecto de ley 
modificando la ley orgánica del Ministerio Público bonaerense, con la finalidad de incorporar las defensorías especializadas para actuar ante el Fuero Contencioso Administrativo.

La propuesta legislativa consistió en la creación de Defensorías Oficiales en el Fuero Contencioso Administrativo en cada departamento judicial, una por cada juzgado de dicho fuero. Establecía la creación de cargos y su forma de distribución. Modificaba el artículo 36 de la Ley $\mathrm{N}^{\mathrm{o}} 14.442$, incorporando al Fuero Contencioso Administrativo y adecuaba las normas de la ley orgánica del Poder Judicial $\left(\mathrm{N}^{\circ}\right.$ 5.827) que se veían alcanzadas por la estructura incorporada a la defensa pública provincial.

El proyecto tramitó por expediente D-1373/13-14, pidiendo su autor la reproducción en 2015 (D-21/15-16).

En fecha 15 de julio de 2016 se expidió la Procuradora General de la Suprema Corte de Justicia, Dra. María del Carmen Falbo, quien expresó lo siguiente: "Adelanto que, en líneas generales, el proyecto de ley en estudio fue acogido en forma favorable en las dependencias a mi cargo. Idéntico criterio sostuvo el Consejo de Defensores al momento de analizar y debatir la propuesta en cuestión", observando un error material del proyecto que omitió una de las defensorías que debía crearse en el Departamento Judicial de San Isidro.

\section{Líneas de investigación-acción}

1. Autonomía de la defensa pública. El problema estructural del Ministerio Público Bonaerense por su deficitario diseño constitucional. Propuesta de reforma al artículo 189 de la Constitución de la Provincia de Buenos Aires

a) Consideraciones generales

La necesidad de garantizar la autonomía de la Defensa Pública-planteada por Organismos Internacionales de Derechos Humanos- resulta una de las problemáticas centrales en torno a la estructura del Ministerio Público de la Provincia de Buenos 
Aires. Ello así, porque este tipo de organización -amparada en una disposición constitucional que no previó la independencia de acusación y defensa- conlleva la vulneración del derecho al debido proceso constitucional-convencional.

Diversos organismos internacionales han tenido posibilidad de pronunciarse acerca de la necesidad de que los Estados adopten medidas tendientes a garantizar la autonomía funcional y financiera de la defensa pública.

De esa forma, se busca no solo desalentar que la defensa oficial no dependa de la misma autoridad que los fiscales, sino que cuente con los mismos recursos humanos y materiales que el Ministerio Fiscal. Ello, con el objetivo de lograr una verdadera paridad de armas y un efectivo ejercicio del derecho de defensa.

En nuestros países, marcados por la gran cantidad de compatriotas excluidos y los numerosos grupos de marcada vulnerabilidad (sectores desaventajados sobre los que más recae la selectividad de la persecución penal y/o los que no cuentan con asistencia letrada gratuita y de calidad para la promoción, exigibilidad y justiciabilidad de sus derechos fundamentales), sumado al aumento constante de la población carcelaria, las pésimas condiciones de alojamiento en unidades y lugares de detención,el empoderamiento personal-ciudadano en la demanda de bienes y servicios públicos y la consolidación de un enfoque de derechos desde el cual disputar la juridicidad de los DESCA en socieades estructuralmente desiguales, han generado un aumento significativo de la demanda del servicio de defensa pública. De allí la necesidad de: (i) dotar de mayores recursos a su estructura, equiparándolos con los ministerios fiscales; y, (ii) repensarla función, razón de ser y límites de actuación del propio Ministerio Público (Fiscal y de la Defensa) en la protección de bienes socialmente relevantes. Esto es, qué rol debe asumir en la discusión y resolución de conflictos de interés público (por ejemplo, causas de libertad de expresión, concentración económica, corrupción o DESCA).

La Corte Interamericana de Derechos Humanos tuvo oportunidad depronunciarse en el caso "Ruano Torres" sobre la 
necesidad de garantizar igualdad de armas entre la Defensa Pública y el poder persecutorio, señalando la exigenciade disponer de "(...) defensores idóneos y capacitados que puedan contar con autonomía funcional. (...) La Asamblea General de la OEA ha instado a los Estados a que adopten acciones tendientes a que los defensores públicos oficiales cuenten con presupuesto adecuado y gocen de independencia, autonomía funcional, financiera y/o presupuestaria y técnica" (caso "Ruano Torres y Otros VS. El Salvador", sentencia de 5 de octubre de 2015,Fondo, Reparaciones y Costas, párr. 159).

En igual sentido sostuvo la Corte Interamericana en el caso "Barreto Leiva" que "el derecho a la defensa técnica no puede ser satisfecho por quien a la postre realizará la acusación, esto es, el Ministerio Público. La acusación afirma la pretensión penal; la defensa la responde y rechaza. No es razonable depositar funciones naturalmente antagónicas en una sola persona" (caso "Barreto Leiva Vs. Venezuela", sentencia de 17 de noviembre de 2009, Fondo, Reparaciones y Costas, párr. 63).

Por su Parte, la Asamblea General de la Organización de Estados Americanos se ha pronunciado sobre la cuestión en reiteradas oportunidades. Por ejemplo, mediante Resolución AG/RES No 2656 (7-VI-2011) "Garantías para el acceso a la justicia. El rol de los defensores oficiales", en la que dispuso: "Recomendar a los Estados Miembros que ya cuentan con el servicio de asistencia letrada gratuita que adopten acciones tendientes a que los Defensores Públicos Oficiales gocen de independencia y autonomía funcional" (apartado 4). En el mismo sentido, la AG/RES. No 2801 (5 de junio de 2013) "Hacia la autonomía de la Defensa Pública Oficial como garantía de acceso a la justicia", estableció en sus apartados 3,4 y 5: "3. Afirmar la importancia fundamental que tiene el servicio de asistencia letrada gratuita prestada por los Defensores Públicos Oficiales para la promoción y protección del derecho de acceso a la justicia de todas las personas, en particular de aquellas que se encuentran en una situación especial de vulnerabilidad en todas las etapas del proceso. 4. Reiterar una vez más a los Estados Miembros 
que ya cuentan con el servicio de asistencia letrada gratuita que adopten acciones tendientes a que los defensores públicos oficiales gocen de independencia, autonomía funcional, financiera y/o presupuestaria y técnica. 5. Sin perjuicio de la diversidad de los sistemas jurídicos de cada país, destacar la importancia de la independencia, autonomía funcional, financiera y/o presupuestaria, de la defensa pública oficial, como parte de los esfuerzos de los Estados Miembros para garantizar un servicio público eficiente, libre de injerencias y controles indebidos por parte de otros poderes del Estado que afecten su autonomía funcional y cuyo mandato sea el interés de su defendido o defendida."

En términos similares se ha pronunciado la Asamblea General de la OEA en las Resoluciones No 2817; 2887; 2907; y, 2928.

Entre tanto, el Comité de Derechos Humanos de la Organización de Naciones Unidas en relación a las observaciones sobre los informes presentados por nuestro país en el año 2010, señaló que "El Comité nota con preocupación que, pese a que un alto porcentaje de personas detenidas y procesadas no cuenta con defensor de su elección y debe utilizar los servicios de la Defensoría Pública, ésta no cuenta con los medios necesarios para proporcionar en todos los casos una asistencia jurídica adecuada. Nota igualmente que, pese a lo previsto en el artículo 120 de la Constitución, la autonomía funcional y presupuestaria de la Defensoría Pública respecto de la Procuraduría no está garantizada en todo el territorio nacional, lo que tendría un impacto negativo en la calidad de los servicios prestados por aquélla (Artículo 14 del Pacto)". (Obs. No 20, Comité de Derechos Humanos, $98^{\circ}$ período de sesiones, Nueva York, 8 a 26 de marzo de 2010).

El Ministerio Público en nuestra provincia se encuentra afectado por una falla estructural surgida de la propia voluntad constituyente. Pues bien, el artículo 189 de la Carta provincial, no solo no ha consagrado su independencia, autonomía funcional y autarquía financiera, sino que además depositó en cabeza del Procurador General la superintendencia sobre todos los demás miembros del Ministerio Público. 
Esto último genera una situación anómala y contradictoria en donde la defensa y la acusación dependen de la misma autoridad, con la consiguiente afectación de las garantías del debido proceso y el efectivo acceso a la justicia que ello supone.

Ante un problema estructural como el señalado, deberíamos pensar en alguna solución de fondo que logre disipar la objeción y llevar certidumbre al funcionamiento de una institución tan relevante y sensible como el Ministerio Público. Es por ello que, teniendo en cuenta las herramientas que el propio sistema constitucional bonaerense nos brinda, propiciamos el debate de una eventual reforma constitucional por vía de "enmienda" que permita resolver la situación descripta.

\section{b) Los procedimientos de reforma constitucional establecidos en la Constitución Bonaerense}

En el artículo 2 de la Constitución local quedó expresamente establecido que el pueblo de la Provincia (a través de sus representantes), podrá reformar la Constitución de acuerdo y mediante los procedimientos que la misma Ley Fundamental establece. Las vías habilitadas para una posible reforma constitucional están previstas en la sección novena (artículos 206, 207, 208 y 209).

El poder constituyente ha sido definido como la atribución soberana del pueblo a darse su ordenamiento político fundamental originario por medio de una Constitución y a revisarla, total o parcialmente, cuando ello sea necesario.

Así, se suelen diferenciar dos clases de poder constituyente: el originario y el derivado. El poder constituyente originario es aquel ejercido para instaurar la primera Constitución de un Estado. De allí que también se lo conoce como "fundacional". En tanto el poder constituyente derivado se ejercita con el objeto de reformar una Constitución anterior. Este último es el supuesto contemplado en la cláusula que estamos analizando.

En los Estados con una organización federal, como es nuestro caso, cabe distinguir el poder constituyente federal o 
de primer grado, del poder constituyente local o provincial (también llamado de segundo grado). Este último, conforme al juego armónico de las prescripciones de los artículos1, 5, 75 inc.12, 121 y concordantes de la CN y 1 de la CP, debe estar subordinado al poder constituyente federal.

Teniendo en cuenta los procedimientos para ser reformadas, las Constituciones escritas suelen clasificarseen flexibles y rígidas.

La Constitución flexible es aquella que puede ser modificada por el mismo órgano que sanciona la ley. Por su parte, la Constitución rígida requiere para su modificación la actividad de un órgano distinto del que sanciona la ley o la del mismo órgano legislativo, pero con exigencias o recaudos diferentes de los exigidos para la ley ordinaria. Esta posibilidad fue establecida por primera vez en la Constitución de los Estados Unidos de 1789.

Sopesando esta clasificación, la Carta bonaerense entra en el grupo de las Constituciones rígidas, toda vez que -según se desprende de los términos del artículo bajo análisis- para su reforma es necesario llevar adelante un procedimiento diferente al previsto para la formación y sanción de las leyes.

Suele hacerse una distinción entre "reforma" y "enmienda" constitucional. Así, la reforma tendría un carácter amplio, mientras que en la enmienda la modificación alcanzaría tan sólo a uno o pocos artículos. A decir verdad, nos inclinamos a pensar que no existen razones fundadas para hacer tal distingo. La CN en su artículo 30 solamente se refiere a "reforma", pudiendo ser ésta total o parcial. Además, a diferencia de la CP (como veremos a continuación), dispone que la reforma únicamente se efectuará por una Convención convocada al efecto.

Veamos ahora cuál fue el procedimiento previsto por el constituyente local para llevar adelante una reforma a la Ley Fundamental de la Provincia.

El artículo 206 propone una doble vía para la reforma constitucional. Así, dos son los procedimientos habilitados para tal fin:

a) La "enmienda" llevada adelante por la Legislatura, y su posterior ratificación popular mediante plebiscito. 
b) La reforma a través de una convención constituyente.

Para ambos supuestos es imprescindible una ley emanada de la Legislatura que declare la necesidad de la reforma. La Constitución requiere que dicha ley cuente con una mayoría calificada ${ }^{14}$.En el caso, el voto afirmativo de los dos tercios del total de los miembros de ambas Cámaras.

La ley que declare la necesidad de la reforma deberá establecer si la misma será total o parcial y, al mismo tiempo, escogerá una de las variantes posibles en cuanto al procedimiento a utilizarse: las enmiendas proyectadas o la convocatoria a una convención constituyente reformadora.

No podemos dejar de mencionar que la interpretación de estas disposiciones constitucionales ha generado debates $y$ puntos de vistas opuestos en la doctrina especializada.

Así, hay quienes entienden que el sistema de "enmienda" por la Legislatura y posterior aprobación popular, debe ser interpretado en sentido restringido, y sólo puede ser utilizado para modificar no más de un artículo.Por el contrario, en criterio que compartimos, se ha sostenido que las reformas -sean éstas amplias o restringidas, alcancen a uno o más artículos- pueden llevarse a cabo por cualquiera de los procedimientos previstos en el artículo 206.

Conviene recordar que siguiendo esta línea de interpretación, la Provincia de Buenos Aires intentó modificar 98 artículos de su Constitución mediante el procedimiento de reforma por la Legislatura y posterior plebiscito en 1989. Dicha reforma no prosperó dado que, al ser sometida a la votación popular, fue rechazada ampliamente por la ciudadanía bonaerense.

En definitiva, la opción por uno de los procedimientos de reforma constitucional previstos en el artículo 206 es una decisión netamente política de la Legislatura local, se trate de modificar uno o más artículos.

14 El constituyente procuró de esta forma que una cuestión tan delicada y excepcional, como lo es reformar la Carta Magna, cuente con un amplio consenso. 
c) La modificación del artículo 189 de la Constitución de la Provincia de Buenos Aires por vía de enmienda. La actuación de las Cámaras Legislativas y el posterior plebiscito. Una propuesta de reforma

La posibilidad de reformar el artículo 189 de la Constitución provincial por vía de enmienda, no solo se ajusta a la propia letra del artículo 206 de la Carta bonaerense, sino que encuentra en la experiencia reciente ejemplos concretos de implementación.

En efecto, la Ley $N^{\circ} 14.523$ sancionada en el año 2013, declaró necesaria la reforma constitucional de la Provincia de Buenos Aires con el objeto de modificar el inciso 3 del artículo 191. Se propició la disminución de la edad requerida para ser electo concejal, bajándola de 25 a 21 años.

Sin embargo, ocurrió algo curioso. No obstante haber entrado en vigencia la ley que declaraba necesaria la reforma parcial, no se dio cumplimiento a la segunda etapa del procedimiento de reforma escogido. Esto es, el plebiscito popular mediante el cual el pueblo de la Provincia ratifica la enmienda constitucional. Así, el artículo $4^{\circ}$ de la Ley $\mathrm{N}^{\circ} 14.523$ estableció que "El Poder Ejecutivo convocará al electorado de la Provincia de Buenos Aires, a partir de la sanción de la presente Ley, a un plebiscito en la primera elección que se realice, para que se exprese en pro o en contra de la enmienda". Esto nunca ocurrió.

En vez de ello, el entonces gobernador Daniel Scioli, emitió el Decreto $\mathrm{N}^{\circ} 422 / 13$, mediante el cual se creaba una Comisión Especial tendiente a disponer lo necesario para la implementación de la ley de reforma constitucional.

\section{La representación del Interés Público ante conflictos de intereses}

A diferencia de lo que sucede en el ordenamiento jurídico federal y de la Ciudad Autónoma de Buenos Aires, no existe intervención oficial de las fiscalíasante la justicia administrativa provincial. 
El código procesal administrativo de la provincia de Buenos Aires (Ley $\mathrm{N}^{\mathrm{o}} 12.008$ y modif.) no tiene regulada la intervención principal ni promiscuadel Ministerio Público provincial a fin de expedirse, por ejemplo, sobre la competencia material, la habilitación de instancia o la afectación de un interés general de la sociedad. Sólo las partes actúan ante el juez.

La presencia de los fiscales ante el fuero contencioso administrativo bien puede ser garantía para evitar conflictos de intereses y de la defensa de los intereses de la sociedad, que en este tipo de proceso judicial se diferencia de los intereses de la Administración Pública y los particulares.

Como se puede percibir de diversas actuaciones judiciales en las que se encuentran en colisión partes con intereses aparentemente similares -como sucedió en la causa "Correo Argentino"-, la defensa del interés de la sociedad estuvo a cargo de la representante del Ministerio Público Fiscal ante el fuero en el que se desarrollaba el juicio.

En otras causas, en las que originariamente la representación del Estado defendía la constitucionalidad de una ley -cuestionada por el actor- y que luego -por un cambio de estrategia procesal- aceptaba que tal norma se oponía a disposiciones de la CN, la defensa de la ley quedó en manos del Fiscal ante la Justicia Contencioso Administrativa interviniente. Por ejemplo, ello ocurrió en las causas en las que se discutía la ley de ingreso irrestricto a las Universidades Públicas ${ }^{15}$.

Las preguntas iniciales que dieron origen a estas reflexiones provisorias que aquí se comparten son: ¿Es el interés público una situación que habilita su defensa judicial? En tal caso; ¿Quién es titular del interés público? ¿La Administración -cuya finalidad es satisfacer el interés público- es la titular? ¿Quién está

\footnotetext{
15 López, José Ignacio y Cabral, Pablo Octavio (2016) “La declaración de inconstitucionalidad de la Ley de Ingreso Irrestricto a las Universidades Públicas. Una interpretación contraria al Derecho Internacional de los Derechos Humanos", publicado en la Revista La Ley de fecha 23 de agosto de 2016, con referato. Extensión 21 carillas (Disponible en SEDICl; http://hdl. handle.net/10915/61425).
} 
legitimado a defender en juicio al interés público? ¿Los intereses de la Administración pública coinciden con el interés público?

A finales del siglo XIX, el jurista alemán J. Mejer explicaba que la Administración Pública tenía como objetivo o finalidad promover los intereses del Estado y los del Pueblo. El concepto de interés estatal y público -en el desarrollo de las sociedades modernas- se fue modificando, transformándose, dificultando una captación fiel que nos permita -si esto fuera posible- observarlo, medirlo, pesarlo, describirlo o analizarlo.

No obstante ello, su existencia adquiere relevancia práctica, ya que es la justificación formal de todas las políticas públicas que se llevan a cabo desde los sucesivos gobiernos que administran el Estado. El interés público es utilizado como una válvula de escape por la Administración Pública en contra de las posturas de individuos o colectivos sociales y, al mismo tiempo, obliga al Estado a cumplir con las reglas del juego en que pretende invocarlo.

Hoy contamos con el precedente de la CSJN que en la causa "Astilleros Alianza", afirmó que; "debe prevalecer el interés público frente a los intereses meramente privados" y precisa: "el mantenimiento de la medida de no innovar decidida podría producir en el Estado graves perjuicios patrimoniales que se derivarían de la paralización de las obras. Gravámenes que también se harían extensivos a la comunidad toda, por el daño que aquella circunstancia traería como consecuencia para el desarrollo social, que un emprendimiento de la magnitud y trascendencia como el que nos ocupa, por sí sólo supone".

Recordemos, como señalamos con anterioridad, que la incorporación de las reformas constitucionales de 1994 reconocieron al debido proceso colectivo como garantía, habilitando a una serie de sujetos como legitimados para exigir derechos en clave colectiva y discutir en cualquier instancia bajo esa modalidad.

La pregunta que nos interpela es si el interés público puede defenderse en un proceso judicial en el que Estado es parte y, en tal caso, quién es el legitimado para defenderlo en esa 
instancia. Finalmente propondremos la necesidad que un organismo constitucional como el Ministerio Público Fiscal asuma un rol de defensa institucional del interés público en los procesos contencioso administrativos o en los de otra naturaleza en que se pongan en juego intereses de tal tipo (por ejemplo, conflictos sobre libertad de expresión), debiendo intervenir en causas en las que esté en juego en bienestar de la sociedad en general.

Explica Luciano Savignano que "en un breve análisis de las estructuras organizativas de los distintos Poderes Judiciales que poseen fueros especializados en temas de derecho administrativo, puede advertirse que en numerosas jurisdicciones se encuentra prevista la creación y consecuente actuación en el proceso deFiscalías en lo Contencioso Administrativo, como órganos especializados del Ministerio Público.Muchas de esas vicisitudes procesalespodrían ser reducidas con la creación deuna figura que coadyuve a establecer unaorientación clara en la materia de la competenciadel Fuero.Dicha actuación redundará paulatinamenteen una celeridad de los procesos con elbeneficio de las personas sometidas a causasjudiciales.La figura a la que aludimos es la de un Agente Fiscal para actuar ante la Justiciaen lo Contencioso Administrativo ytambién ante el Fuero de Ejecuciones Tributarias" ${ }^{16}$.

En el ámbito de la Justicia Contencioso Administrativo Federal, el Ministerio Público interviene en diversas etapas del proceso judicial como una forma de intervención en los procesos no penales.

Explica Juan De Césaris que el interés público que justifica la intervención de las fiscalías en los juicios penales "tiene también correlato a través de la facultad y obligación de participación, en todo proceso judicial no penal, en el que los intereses en conflicto no pueden dejarse a merced de la voluntad de las partes (...) al haber una afectación pública y social que trasciende una expectativa individual o bilateral, nuestro organismo debe

16 Luciano Savignano, "El Ministerio Público Fiscal de la Provincia de Buenos Aires ante el Fuero Contencioso Administrativo y de ejecuciones Tributarias. Una Propuesta", Revista RAP Bs. As. (73/74), pág. 163 y siguientes. 
salvaguardar el equilibrio conculcado que se propaga a toda la comunidad. Es en ese ámbito que encontramos fundamentalmente la defensa de los intereses generales de la sociedad requerida por expreso mandato constitucional" ${ }^{17}$.

En la investigación publicada por el Centro de Estudios de Justicia de las Américas (CEJA) sobre el rol del Ministerio Público en casos no penales en América Latina, se postula que "la actuación del Ministerio Público Fiscal de la Nación en materia Contencioso Administrativo Federal está a cargo de los fiscales y fiscales generales que velan por el debido proceso legal. Tienen como función principal peticionar en las causas en trámite donde estáinvolucrada la defensa de la legalidad y de los intereses generales de la sociedad, en especial, en los conflictos en los que se encuentren afectados intereses colectivos, un interés y/o una política pública trascendente, normas de orden público y leyes no disponibles por los particulares, el debido proceso, el acceso a la justicia, así como cuando se trate de una manifiesta asimetría entre las partes o estén amenazados o vulnerados los derechos humanos, las garantías constitucionales o la observancia de la Constitución Nacional.En materia procesal participan de cuestiones de competencia, habilitación deinstancia, solicitan la recusación con causa de los jueces intervinientes; producen, ofrecen y solicitan la incorporación de prueba, peticionan el dictado de medidas cautelares o dictaminan sobre su procedencia, plantean nulidades e interponen recursos.Asimismo, plantean inconstitucionalidades, interponen las acciones previstas enla Ley $\mathrm{N}^{\circ} 24.240$, intervienen en casos en los que se encuentren en juego daños causados o que puedan causarse al patrimonio social, a la salud pública y al medio ambiente, al consumidor, a bienes o derechos de valor artístico, histórico o paisajístico, en los casos y mediante los procedimientos que las leyes establezcan"18.

\footnotetext{
17 Juan H. De Césaris, Ministerio Público Fiscal y de la Defensa, en la obra dirigida por Silva Palacio de Caeiro, Competencia Federal, La Ley, Buenos Aires, 2012.

18 CEJA, Ángela Ledesma, "El rol del Ministerio Público en casos no penales en América Latina", Santiago de Chile, 2019.
} 
Respecto de la intervención del Ministerio Público Fiscal ante el fuero Contencioso Administrativo Federal, concluye sosteniendo que "en cuanto al rol del Ministerio Público en el fuero, se puede señalar que si bien la normativa anterior guarda relación con el actual art. 31 de la Ley $\mathrm{N}^{\circ} 27.148$, en tanto ya permitía expresamente su participación activa en todas las causas o trámites judiciales en que el interés público lo requiera de acuerdo con el artículo 120 de la Constitución Nacional, a fin de asegurar el respeto al debido proceso, la defensa del interés público y el efectivo cumplimiento de la legislación, así como para prevenir, evitar o remediar daños causados o que puedan causarse al patrimonio social, a la salud y al ambiente, al consumidor, a bienes o derechos de valor artístico, histórico o paisajístico, en los últimos años su función ha tomado especial importancia, al punto de convertirse en un agente principal del proceso."

La propuesta en este punto, puede sintetizarse en las palabras de Savignano, quien ya hiciera un proyecto de modificación legislativa concreto en la publicación referenciada. El mismo señaló que “(...) una propuesta para la solución de las mencionadas controversias, podría ser la creación de un cuerpo de fiscales que actúen principalmente ante los Fueros en lo Contencioso Administrativo y de Ejecuciones Tributarias. En el supuesto de prosperar esta propuestase debería, a su vez, modificar diversas normas orgánicas y de procedimiento a los efectos de la correcta inserción institucional de la figura. Con esta propuesta se pretende que losórganos creados coadyuven a evitar un dispendio de actividad jurisdiccional y a alentar con ello la consolidación de una seguridad jurídica en los procesos, unificando criterios en temas como competencia judicial, habilitación de instancia contencioso administrativa, de constitucionalidad y validez de normas"19.

19 Luciano Savignano, “El Ministerio Público Fiscal (...)”, ob. cit.. 


\section{La defensa de los Derechos Económicos, Sociales,} Culturales y Ambientales (DESCA) en el Fuero Contencioso Administrativo.Problemas estructurales del acceso a la justicia administrativa en la provincia de Buenos Aires

a) Algunas lineas sobre la judicialización de los DESCA

Los derechos económicos, sociales, culturales y ambientales han sido reguladosexpresamente por el derecho internacional a través de los tratados de protección de los Derechos Humanos (Pacto Internacional de Derechos Económicos, Sociales y Culturales; Declaración Americana de Derechos y Deberes del Hombre; Convención Americana de Derechos Humanos y Protocolo Adicional de San Salvador), los cuales adquirieron rango constitucional con la reforma de 1994.

En el contexto interamericano de protección de los derechos humanos, los DESCA son definidos como aquellos derechos fundamentales que posibilitan al individuo una calidad y nivel de vida adecuado a su naturaleza y dignidad. Entre otros, se reconocen como tales el empleo; la seguridad social; vivienda; educación; salud; alimentación; y/o cultura.

La realidad nacional y regional nos impone el desarrollo de garantías eficientes para tutelar y efectivizar los DESCA de gran parte de la población que se encuentra aún excluida de los beneficios que la comunidad reconoce a los incluidos en ella. Estas técnicas o mecanismos de tutela de los derechos, destinados a lograr su efectividad, pueden ser tanto institucionales (políticas o jurisdiccionales) como extrainstitucionales o sociales (acceso a la información y participación de la ciudadanía).

Así, tanto a nivel federal, como en el ámbito bonaerense, la revisión judicial de las políticas públicas y la consiguiente efectivización de los DESCA es principal (aunque no excluyentemente) competencia de la justicia contencioso administrativa. Por ejemplo, la discusión sobre el alcance de una prestación con una prepaga (sea aún en términos de vínculo contractual), involucra el derecho a la salud. Lo mismo puede decirse en 
relación a la disolución de un vínculo contractual, donde se pone en juego el derecho al trabajo. En ese sentido, debemos tener siempre presente que la constitucionalización del derecho supuso erradicar la insularidad que el derecho privado había construido, poniendo en la escena pública la discusión en torno a la distribución igualitaria de bienes y servicios para la satisfacción de derechos. En esa clave de lectura, los principios de indivisibilidad e interdependencia de derechos son trascendentales para entender la potencia del enfoque de derechos y la inexistencia de jerarquías.

A partir de las reformas constitucionales de la década de 1990 fueron creados en la Ciudad Autónoma de Buenos Aires y en la jurisdicción provincial bonaerense nuevos organismos judiciales descentralizados con competencia material de derecho público. La puesta en funcionamiento de estos tribunales permitió el desarrollo de una jurisprudencia de efectivo control de las políticas sociales de los Estados y la garantía de los DESCA en dicho ámbito judicial.

En nuestra provincia existía una falta de tradición cultural sobre la posibilidad de judicializar los DESCA, en parte debido a la resistencia del propio Poder Judicial para resolver cuestiones de apariencia típicamente política y en parte causada por el desconocimiento del sistema de derechos reconocidos en los tratados de protección de los derechos humanos. Esta resistencia cultural está siendo superada por la labor de los magistrados del Fuero Contencioso Administrativo y el empeño de muchos defensores oficiales que litigan en esta materia, aún cuando -como veremos- no cuentan con una estructura y habilitación especial para intervenir ante dicho fuero especializado.

Frente a la clásica defensa de la tradicional justicia contencioso administrativa se opone una visión socializante y transformadora del rol de los jueces en nuestra sociedad, que también se articula con una concepción participativa de una democracia en la que los derechos fundamentales son garantizados por el Estado en forma igualitaria. 
El poder judicial comenzó a intervenir activamente en las decisiones públicas a través del control de constitucionalidad de las leyes (en nuestro país en forma difusa, es decir tal declaración puede ser emitida por cualquier juez) y mediante el control de legalidad del accionar de las administraciones públicas (especialmente mediante el control efectuado por la justicia contencioso administrativa).

También las reformas de las Constituciones estaduales generalizaron el control de la administración mediante la creación de un nuevo fuero descentralizado con especialidad administrativa. Así desde hace unos años tanto en la Ciudad Autónoma de Buenos Aires como en la provincia del mismo nombre, funcionan los juzgados en lo contencioso administrativo que desarrollan una actividad de control de las respectivas administraciones públicas.

Esta combinación entre reconocimiento de derechos sociales y activismo judicial en el control de las acciones del gobierno (denominada por algunos medios judicialización de la política), tanto en su esfera legislativa como administrativa, generó un espacio institucional de discusión racional de las decisiones públicas del gobierno.

\section{b) La participación del Ministerio Público en la defensa de los DESCA}

Independientemente de cuál sea nuestra concepción acerca de los derechos humanos, estos constituyen obligaciones jurídicas exigibles con relación al Estado (u otras personas), los cuales deberán garantizarse a través de la formulación de políticas públicas y/o reglamentaciones de distinta índole, de la consiguiente asignación de recursos, ventajas o desincentivos y de su potencial justiciabilidad.

De ese modo, no existen, en el plano normativo, generaciones de derechos. En consecuencia, las distinciones que en función de estas categorías se han construido y sostenido, resultan no sólo carentes de sustento y sentido, sino que se perciben 
contraproducentes e irreconciliables con la idea misma del propio reconocimiento. Ello así, pues la formulación de divisiones jurídicas y la instrumentación de distintos grados de satisfacción en correlación a la "jerarquía" que se les asigna, choca con la realidad material única del ser humano, con la indivisibilidad e interdependencia de sus derechos en pos de la realización de su persona y plan de vida y con la asignación de prioridades constitucionalmente adoptadas en el programa de gobierno que el acuerdo social supone.

De allí que la no operatividad (más) inmediata y sustantiva de gran parte de los derechos humanos -en particular, de los DESCA- y de su exigibilidad por parte de los sectores más desaventajados, tiene que ver más con una (hegemónica) concepción conservadora -histórica, filosófica, política, ideológica, económica y jurídicamente instituida- que ha marcado la agenda, sentido y universo simbólico de los mismos, que con falta o carencia de recursos presupuestarios, limitaciones competenciales, imposibilidades técnicas o colapsos institucionales.

En consecuencia, a pesar de los reparos que puedan realizarse a las fórmulas de reconocimiento de derechos contenidas en los instrumentos jurídicos, su lectura, interpretación y aplicación en perspectiva de derechos humanos por parte de los distintos actores, organismos técnicos y movimientos sociales en cada uno de los espacios institucionales o de disputa de significación social, permite/iría aportar umbrales de exigibilidad y operatividad aceptables dentro de una sociedad cada vez más fragmentada, desigual y polarizada. Es decir, que más allá de las distancias que se han construido jurídicamente como expresión de poder en función de cierta clase de intereses, el instrumental con que se cuenta puede servir para la construcción de arreglos institucionales más igualitarios.

Es que la falta de proposición y concreción de cambios significativos en pos de una mayor redistribución del bienestar individual y social en términos de acceso real, garantía y satisfacción de derechos está asociada a la resistencia del poder 
instituido, político estadual o "mercantil", de sus actores, agentes y organización, para ceder beneficios o ventajas que irían en detrimento de sus propios intereses o de los intereses que protegen. ${ }^{20}$

En este contexto, ¿qué herramientas puede aportarnos la existencia de un Ministerio Público de la Defensa autónomo? ¿Por qué es relevante que tal institución exista?

Entre los condicionantes sociales que alteran el acceso a la justicia se destaca en nuestro país la imposibilidad del afectado de costear los gastos que acarrea iniciar una acción judicial. Debe considerarse como fundamental, a fin de garantizar el efectivo acceso a la justicia, la existencia de un servicio de asistencia jurídica gratuita y la eliminación de los costos del proceso.

Las defensorías que hoy por hoy existen en la provincia entienden únicamente en causas civiles y penales no existiendo asistencia estatal en materia contencioso administrativa. En la provincia de Buenos Aires, el servicio de defensa pública que el Estado brinda a sus ciudadanos es ejercido por la Procuración General ante la Suprema Corte de Justicia.

Como vimos, la Constitución bonaerense dispone en su artículo 189 que el Ministerio Público será desempeñado por el procurador y subprocurador general de la Suprema Corte de Justicia; por los fiscales de Cámaras, quienes deberán reunir las condiciones requeridas para ser jueces de las Cámaras de Apelación; por agentes fiscales, asesores de menores y defensores de pobres y ausentes, quienes deberán reunir las condiciones requeridas para ser jueces de primera instancia. El procurador general ejercerá superintendencia sobre los demás miembros del Ministerio Público.

En la estructura del Poder Judicial de la provincia, la reforma constitucional bonaerense del año 1994, estableció la

20 Valga como ejemplo las interpretaciones de ciertos jueces con relación a situaciones de violaciones graves e intolerables a los derechos humanos de personas en situación de extrema pobreza o la falta de formulación de políticas públicas estructurales e integrales. 
creación de un nuevo Fuero Contencioso Administrativo para intervenir en la revisión de la actuación u omisión de las administraciones provincial y municipales (art. $166 \mathrm{CP}$ ), integrado en la actualidad con, al menos un juzgado de primera instancia por cada Departamento Judicial (a excepción de Mar del Plata, La Plata, San Martín y San Isidro en los que se incorporaron más organismos) y por cuatro cámaras de apelaciones regionales (en los Departamentos Judiciales de La Plata, San Nicolás, San Martín y Mar del Plata).

En el actual estado de la defensa pública bonaerense, las personas de escasos recursos que se vean obligados a exigir judicialmente a los Estados provincial o municipales por la efectividad de sus derechos humanos básicos (salud, alimentación, vivienda, educación, etc.) carecen de la asistencia jurídica gratuita, ya que -como vimos- la normativa vigente no le otorga tal competencia al Ministerio Público.

Al mismo tiempo, las transformaciones operadas a la luz de la constitucionalización, la consolidación del enfoque de derechos, la irrupción de la dimensión no sólo individual de la exigibilidad de los DESCA sino también colectiva y las particularidades propias del fuero contencioso administrativo, imponen en cabeza de esa estructura la adquisición de una serie de conocimiento, destrezas y habilidades fundamentales para un adecuado cumplimiento de su mandato constitucional: la defensa de los derechos humanos, el interés público y la juridicidad.

En este marco, el litigio se resignifica como un foro político explícito y el juez como un brazo de esa disputa política, donde se define el alcance concreto de los derechos. A través de su ejercicio se controlan y construyen las líneas de intervención y regulación estatal, disputando la agenda de gobierno. En una estructura institucional caracterizada por su elitismo epistémico, desconfianza hacia la ciudadanía, pluralidad de controles internos ineficientes y ausencia de reaseguros exógenos, la existencia de una defensa pública autónoma, especializada y 
técnicamente solvente constituye una herramienta esencial para viabilizar el empoderamiento individual-colectivo, visibilizar la conflictividad y promover cambios en clave estructural.

\section{Políticas de género en el Ministerio Público bonaerense}

Existen numerosos instrumentos jurídicos internacionales que garantizan la plena vigencia de los derechos humanos para todas las personas, sin distingos de ninguna clase (Carta de las Naciones Unidas, Declaración Universal de Derechos Humanos, Pacto Internacional de Derechos Civiles y Políticos, Pacto Internacional de Derechos Económicos, Sociales y Culturales, Carta de la Organización de los Estados Americanos, Convención Americana sobre Derechos Humanos), así como instrumentos específicos que protegen a las mujeres (Convención sobre la Eliminación de Todas las Formas de Discriminación contra la Mujer -CEDAW- y/o Convención Interamericana para Prevenir, Sancionar y Erradicar la Violencia contra la Mujer).

Nuestro derecho interno también asegura la igualdad y el derecho de no discriminación para todas las personas y contiene leyes específicas para la protección de los derechos de las mujeres. Sin embargo, también en nuestro país las mujeres constituyen un grupo históricamente discriminado que se encuentra en situación de vulnerabilidad. Es el mismo caso de las personas discriminadas por su identidad sexo-genérica.

En la práctica judicial existen numerosos obstáculos al acceso a los derechos que nuestro sistema normativo les otorga. Tanto el derecho como el sistema de justicia fueron diseñados e implementados respondiendo a necesidades masculinas que se entendieron como universales, por lo que las normas, las instituciones y las prácticas jurídicas y judiciales tienden a invisibilizar las experiencias y las necesidades específicas de estos grupos. Las barreras para acceder a la justicia se originan en estereotipos de género y de diversidad sexual que impiden y obstruyen el efectivo goce de los derechos, de acuerdo a estándares internacionales. 
Al respecto, las Observaciones finales sobre el séptimo informe periódico de la Argentina (2016) del Comité CEDAW, y el Informe de la Relatora Especial sobre la violencia contra la mujer, sus causas y consecuencias, relativo a su misión al país (2016), contienen una serie de recomendaciones al Estado en la temática, muchas de cuales son responsabilidad del Ministerio Público.

También encontramos recomendaciones que incumben a dicha institución en las Observaciones finales sobre el quinto informe periódico de la Argentina (2016) del Comité de Derechos Humanos y en las Observaciones finales sobre el cuarto informe periódico de la Argentina (2018) del Comité de Derechos Económicos, Sociales y Culturales.

Conforme lo dispuesto por el artículo 1 de la Ley $\mathrm{N}^{\circ} 14442$ y modificatorias, el Ministerio Público de la Provincia de Buenos Aires tiene legitimación plena para actuar en defensa de los intereses de la sociedad y en resguardo de la vigencia equilibrada de los valores jurídicos consagrados en las disposiciones constitucionales y legales.

Por lo tanto, constituye una manda legal la incorporación de perspectiva de género y de diversidad sexual en el diseño e implementación de políticas públicas que reconozcan a las mujeres y personas discriminadas por su identidad sexogenérica como sujetos diferenciados, y que garanticen el acceso efectivo a mecanismos judiciales eficaces y respetuosos de sus derechos.

Asimismo, como política interna del organismo, debe adoptar medidas con perspectiva de género y diversidad sexual para garantizar la igualdad de ingreso y carrera, como así también la igualdad en el ámbito de las relaciones interpersonales de quienes lo integran.

Frente a esta problemática compleja, deviene necesario impulsar la creación de un área específica que articule con sus distintas dependencias para abordar las problemáticas propias de cada una de ellas, promoviendo la transversalización de la 
perspectiva de género y diversidad sexual para el efectivo ejercicio de los derechos económicos, sociales, civiles, políticos y culturales de las mujeres y de las personas discriminadas por su identidad sexo-genérica. También para brindar capacitación, asesoramiento y asistencia técnica tanto a fiscales, defensoras y defensores, asesoras y asesores de incapaces como a las demás personas integrantes de su estructura, sobre cuestiones de género y diversidad sexual que se presenten en el desarrollo de sus funciones.

Todo ello supone la necesidad de abordar esta materia con estructuras especializadas, con sensibilización y formación específica, con dedicación exclusiva a la temática y recursos acordes.

Dada las particularidades de las actuaciones del Ministerio Público Fiscal y de la Defensa, y lo normado en los artículos 2 y 4 de la Ley $\mathrm{N}^{\circ} 14.442$ cuando señalan, respectivamente, que “(...) El Ministerio Público se compone por el Ministerio Público Fiscal y el Ministerio Público de la Defensa como áreas funcionalmente autónomas" y que "El servicio de la Defensa Pública goza de autonomía funcional, independencia técnica (...)", podría pensarse en la creación de dos áreas diferentes o dos subáreas, para permitir de este modo un abordaje diferenciado responsable y eficiente de la temática en cuestión. De esta manera, el Ministerio Público bonaerense dará cumplimiento a lo requerido por la Comunidad Internacional, nuestro ordenamiento interno y lo reclamado por nuestra sociedad.

\section{Fundamentación}

\section{Regulación constitucional y legal}

El Ministerio Público es el cuerpo de Fiscales, Defensores Oficiales y Asesores de Incapaces que, encabezado por el Procurador General, actúa con legitimación plena en defensa de los intereses de la sociedad y en resguardo de la vigencia equilibrada de los valores jurídicos consagrados en las disposiciones constitucionales y legales (art. 1, Ley $\mathrm{N}^{\mathrm{o}}$ 14.442). 
Apartándose de las disposiciones de la CN reformada en 1994 -que le dedicó una sección especial al Ministerio Público, asegurando su carácter independiente, autonomía funcional, autarquía financiera, la inmunidad funcional e intangibilidad de los sueldos de sus miembros-, la Carta provincial no contempló ninguno de esos extremos en el artículo que estamos comentando.

Como acertadamente se ha señalado, la convención constituyente provincial reunida en 1994 desperdició la oportunidad de adecuar la estructura de este órgano a las necesidades actuales, generando así un vacío constitucional sobre las funciones que ejerce el Ministerio Público, su independencia y autonomía y las garantías funcionales acordadas a sus integrantes. Si bien el presente artículo fue modificado en 1994, la reforma sólo se limitó a incorporar la figura del Subprocurador.

Como consecuencia de las carencias mencionadas, el legislador -a través de la ley orgánica- se encargó de fijar precisiones sobre esta fundamental institución.

En línea con la presente norma constitucional, la ley dispuso que el Procurador General estará a la cabeza del Ministerio Público y ejercerá la superintendencia sobre todos sus integrantes. Los miembros del Ministerio Público tienen los mismos derechos e inmunidades que los jueces. Conservan sus cargos mientras dure su buena conducta y solamente pueden ser suspendidos o removidos, conforme a los procedimientos de juicio político o enjuiciamiento previstos en los artículos 73 , inciso 2) y 182 de esta Constitución.

Casi la totalidad de las constituciones provinciales extienden la garantía de la inamovilidad a los miembros del Ministerio Público. La Carta bonaerense solo se limita a establecer los requisitos para ocupar los cargos, siendo la inamovilidad consagrada en la ley reglamentaria. Mencionamos como excepciones a tal principio el artículo 126 de la Constitución de la Ciudad de Buenos Aires, el cual establece para el Fiscal General una duración en su cargo de siete años, pudiendo ser reelegido. Algo similar ocurre con la Constitución de Córdoba,la que dispuso 
que el Fiscal General dura en sus funciones cinco años y puede ser designado nuevamente.

A la hora de analizar la evolución del Ministerio Público de los últimos años, tenemos que tener presente que en 1997 se llevó a cabo una profunda reforma en materia procesal penal en el ámbito bonaerense.

En efecto, durante la gobernación de Eduardo Duhalde tuvo lugar un ambicioso plan de reformas estructurales que desembocaron en un nuevo paradigma de persecución penal. Se pasó de un sistema inquisitivo y escrito (donde el magistrado que llevaba la investigación, luego era el mismo que dictaba la sentencia) a uno acusatorio, de tipo oral y con una investigación penal preparatoria al debate a cargo del agente fiscal.

En ese contexto, se debió pensar en una nueva normativa para el rol del Ministerio Público y su articulación con las demás instituciones y actores del sistema penal. Así fue sancionada la Ley $\mathrm{N}^{\mathrm{o}} 12.061$ por medio de la cual se buscó ordenar la autonomía e independencia del organismo y organizarlo jerárquicamente bajo la figura del Procurador General.

Tiempo más tarde fue sancionada por la legislatura local una nueva ley orgánica del Ministerio Público (Ley $\mathrm{N}^{\circ}$ 14.442) en el año 2013. La misma parte del principio general que el Ministerio Público es parte integrante del Poder Judicial y goza de la autonomía e independencia que le otorga la Constitución para el debido cumplimiento de sus funciones, siendo su organización jerárquica y regida por los principios de unidad, flexibilidad y descentralización.

Tal vez la reforma más trascendente de la Ley $\mathrm{N}^{\circ} 14.442$ ha sido la consolidación del principio de "autonomía de la defensa pública". Fue así que el texto legal estableció que "el servicio de la Defensa Pública goza de autonomía funcional, independencia técnica y autarquía financiera y es prestado por los defensores oficiales" (art. 4).

En función de ello, la propia ley dispuso que el Ministerio Público estaría compuesto por el Ministerio Público Fiscal y el 
Ministerio Público de la Defensa como áreas funcionalmente autónomas. Por tal motivo el legislador creó la figura del Defensor General de la Provincia, responsable, según la norma, del adecuado funcionamiento del Ministerio Público de la Defensa con potestades y atribuciones de definir políticas de la defensa pública, dictar instrucciones generales y particulares, ejercer acciones disciplinarias y disponer del personal de su área.

Para el desempeño del cargo de Defensor General -como para el de Subdefensor General creado por la misma norma-, se exige los mismos requisitos que para ser miembro de la Suprema Corte de Justicia (art. 177, CP). En cuanto al nombramiento, resulta de aplicación el procedimiento previsto en el artículo 175 segunda parte. Es decir, serán designados por el Poder Ejecutivo a partir de una terna elevada por el Consejo de la Magistratura y requerirán acuerdo del Senado en sesión pública.

Desde hace años, el principio de la "autonomía de la defensa pública" constituye una cuestión que ya no admite debates, tanto en nuestro país como a nivel internacional. En efecto, debemos partir de la base que la normativa internacional de protección de derechos humanos exige que a toda persona sometida a un proceso (ya sea de tipo penal, civil, laboral o el que fuera) se le deben respetar las garantías de un debido proceso legal.

Dentro de ellas adquiere una importancia fundamental la asistencia de una defensa técnica adecuada y eficaz para hacer efectivo el derecho de acceso a la justicia. Llegado el caso que una persona sometida a proceso carezca de medios económicos para nombrar un defensor particular, será el Estado quien asuma de manera gratuita esa asistencia técnica a través de la defensa oficial (ver comentario al artículo 15 de la CP referido a la tutela judicial efectiva).

A la luz de lo que venimos comentando, resulta claro advertir la necesidad de hacer efectivo el principio de autonomía de la defensa pública para el fortalecimiento de sus funciones. Pensemos que en la Provincia de Buenos Aires, históricamente la defensa pública dependió del Procurador General, que a su 
vez ejerce la jefatura sobre los fiscales (contradictores procesales de la defensa).

Esta posición anómala en donde el superior del fiscal y del defensor es el mismo funcionario, podría generar situaciones no deseadas para una buena administración de justicia. Por ejemplo, que los defensores teman ser pasibles de sanciones disciplinarias por el ejercicio comprometido de sus funciones; de ver recortadas sus asignaciones presupuestarias; o, limitar o condicionar sus ascensos.

En el plano internacional, la propia Asamblea General de la OEA (organización de Estados Americanos) viene sosteniendo hace tiempo sobre la necesidad de que los Estados miembros adopten las medidas necesarias para dotar al servicio de defensa pública de autonomía funcional y garantizar de esa forma el derecho de acceso a la justicia, en especial de aquellas personas que se encuentran en situaciones de vulnerabilidad.

En nuestro país, tal como lo mencionamos anteriormente, la reforma a la Constitución Nacional de 1994 diseñó un modelo de defensa autónoma. De acuerdo a su artículo 120, el Ministerio Público está integrado por un Procurador General y por un Defensor General. Pero como bien se ha señalado, tal diseño a nivel federal no tuvo el impacto esperado sobre la organización de las defensas públicas de todas las provincias del país.

Volviendo al ámbito de la Provincia de Buenos Aires, debemos señalar que al sancionarse la nueva ley orgánica del Ministerio Público (Ley $\mathrm{N}^{\circ}$ 14.442), la entonces Procuradora General presentó, antes de que la misma entrara en vigencia, una acción originaria de inconstitucionalidad ante la Suprema Corte. Mediante aquella acción solicitó se prohíba la implementación de la nueva normativa por hallarla contraria a la Constitución provincial.

Entre sus fundamentos planteó que, una modificación como la que se pretendía, solo podía ser factible mediante una reforma constitucional y no por vía legislativa. Consideró que la creación del cargo de Defensor General con la misma jerarquía que el Procurador violentaba el artículo 189 de la Carta provincial. 
La Suprema Corte en su decisión no se pronunció sobre el fondo de la cuestión como así tampoco sobre la medida cautelar solicitada. Tan solo dejó establecido que "hasta tanto se resuelva, las competencias y facultades asignadas por la ley cuestionada deben ser ejercidas por el Procurador General en tanto cabeza del Ministerio Público y titular de la superintendencia sobre la totalidad de los demás miembros que lo integran (arts. 189, Const. Prov. y $1^{\circ}, 2^{\circ}$ y 20 , 1er. párr., ley 14.442 ; art. 34 inc. $4^{\circ}$ y $5^{\circ}$, C.P.C. y C.)”. Esta situación excepcional continúa hasta la actualidad, y demuestra la clara resistencia de ciertos sectores a una verdadera implementación del principio de la autonomía de la defensa pública. Hasta el día de hoy no se ha llamado a concurso para cubrir los cargos de Defensor y Subdefensor General.

\section{Proyectos de reforma de la ley orgánica del Ministerio Público provincial}

Destacamos entre los antecedentes de reforma de la ley orgánica del Ministerio Público, previo a la sanción de la ley 14.442, los siguientes:

1) Proyecto de ley del Diputado Fernando Navarro, tramitado por Expediente D-2877/08-09, sin finalmente ser aprobado por la legislatura provincial.

2) Anteproyecto de reforma del Dr. Jorge Taiana.

\section{Suspensión cautelar de la ley 14.442. Sentencia de la} SCBA en la Causa I. 72.447 "Procuradora General contra Provincia de Buenos Aires. Inconstitucionalidad ley 14.442”

a) Principales consideraciones

El dictado de sentencia en la causa referida y el sentido de dicha decisión judicial resultó un gran paso hacia la autonomía de la Defensa Pública en la Provincia de Buenos Aires.

El pasado 29 de mayo, el Máximo Tribunal de la Provincia se pronunció de forma categórica y por unanimidad de sus 
miembros, acerca de la constitucionalidad de la Ley $\mathrm{N}^{\circ}$ 14.442, la que entre otras cuestiones estableció expresamente que la Defensa Pública goza de autonomía funcional, independencia técnica y autarquía financiera. Al así resolver, vino a poner fin a una situación de incertidumbre que se prolongó durante años en nuestra provincia, con la grave afectación a la vida institucional que ello significaba.

Como ya se ha señalado anteriormente, al sancionarse la ley 14.442 en el año 2013 la entonces Procuradora General interpuso una acción originaria de inconstitucionalidad ante la Suprema Corte de Justicia de la Provincia de Buenos Aires que generó en la práctica la suspensión de la aplicación de la norma impugnada.

En su objetivo de lograr la invalidez de la Ley $\mathrm{N}^{\circ} 14.442$, la Procuradora desplegó en su presentación básicamente dos agravios: a) Que la norma sancionada por la Legislatura no habría cumplido los estándares mínimos de debates en las cámaras; b) Que la creación de los dos nuevos cargos de Defensor General y Subdefensor General y la atribución a ellos conferida de ser los responsables del adecuado funcionamiento del Ministerio Público de la Defensa, resultaría contraria a la Constitución provincial.

En cuanto al primer planteo (la supuesta falta de deliberación legislativa) la Suprema Corte sostuvo con meridiana claridad que, si bien el tratamiento en la Legislatura local de la Ley $\mathrm{N}^{\mathrm{o}} \mathbf{1 4 . 4 4 2}$ pudo no ser el óptimo, debe tenerse en cuenta que el debate parlamentario no fue completamente obviado y que la referida ley "I) concierne a un aspecto organizativo de uno de los poderes públicos; II) no establece una vinculación directa con los derechos de las personas; III) modifica parcialmente un esquema legal preexistente; IV) reconoce como antecedentes varias iniciativas legislativas propuestas en los últimos años; V) fue acompañada por un mensaje o exposición de fundamentos; IV) en principio tiende a una mejor tutela de los derechos; VII) no sacrifica bienes jurídicos ni instaura un cuadro de regresividad normativa". Por todo ello, se inclinó a no tachar 
la norma impugnada como irrazonable ni mucho menos como contraria a ninguna disposición de la Carta provincial.

En cuanto al segundo agravio planteado por la parte actora (que la norma cuestionada colisionaría con lo dispuesto por el art. 189 de la Constitución provincial), la Corte-con voto del Dr. Soria-, en un extenso razonamiento que abarcó desde aspectos históricos, pasando por antecedentes de iniciativas legislativas sobre la temática en cuestión y hasta pronunciamientos de organismos internacionales en materia de Derechos Humanos, llega a la firme conclusión que la Ley $\mathrm{N}^{\mathrm{o}} 14.442$ no infringe de manera alguna el orden constitucional.

Por último señalamos que, por decisión del legislador, integran el Ministerio Público:

i) El Procurador General de la Suprema Corte de Justicia.

ii) El Subprocurador General de la Suprema Corte de Justicia.

iii) El Defensor General de la Provincia de Buenos Aires.

iv) El Subdefensor General de la Provincia de Buenos Aires.

v) El Fiscal y el Defensor del Tribunal de Casación.

vi) Los Fiscales de Cámara y los Defensores Departamentales.

vii) Los Adjuntos del Fiscal y del Defensor del Tribunal de Casación.

viii) Los Agentes Fiscales y los Defensores Oficiales.

ix) Asesores de Incapaces.

x) El Cuerpo de Magistrados Suplentes del Ministerio Público.

\section{b) Jurisprudencia}

Una comprensión sistemática del ordenamiento permite concluir que hasta tanto comiencen su actividad los nuevos órganos creados de la defensa pública, las competencias que la Ley $\mathrm{N}^{\mathrm{o}} 14.442$ confiere al Defensor General provincial (y 
Sub Defensor provincial) en sustitución de las originariamente asignadas al Procurador General, podrán ser desempeñadas por éste dada su cualidad de titular Ministerio Público (arts. 189, CP y 1 y 2 , Ley $\mathrm{N}^{\circ}$ 14.442). Ello así, a fin de asegurar la continuidad de un conjunto de órganos y servicios indispensables para el respecto a la garantía de la tutela judicial continua y efectiva que la Constitución manda a preservar (art. 15, CP). El mismo temperamento cabe aplicar respecto de las funciones hoy día confiadas a otras autoridades de la defensa (art. 18 inc. 5, ley 12.061, según ley 14.221; 24 inc. 3, ley 14.442). ["Procuradora General de la Suprema Corte de Justicia de la Provincia de Buenos Aires c/Provincia de Buenos Aires s/Inconstitucionalidad de ley 14.442”. SCBA LP I 72447 I 11/03/2013 Juez SORIA (OP)].

El Ministerio Público como representante de la comunidad tiene el derecho y el deber de promover la adopción de todas aquellas medidas que estime pertinentes para el debido esclarecimiento de los hechos. Si así no fuera, la defensa de la comunidad que le ha sido encomendada, resultaría enervada. Esa amplia facultad sólo encuentra límite en la decisión del magistrado interviniente que consentirá o no la instrumentación de la medida solicitada (JEMF LP 966 RSI-966-93 I 9-12-1993, "Alemano s/Enjuiciamiento").

\section{Actividades}

Entre las acciones que se proponen, destacamos:

a) Mesa de discusión y trabajo.

b) Jornadas Ministerio Público de la Provincia de Buenos Aires. Perspectivas y nuevos desafíos institucionales frente a la sociedad bonaerense (CIDerCrit FCJyS UNLP)

c) Entrevistas a informantes claves.

d) Grupo de discusión conversatorios coordinado por miembros del CiDerCrit.

e) Presentación pública del proyecto de reformas legislativas para un nuevo Ministerio Público de la Provincia de Buenos Aires. 
f) Presentación pública de una propuesta de reforma constitucional.

g) Publicación del presente programa, los avances y acciones en la Revista Derechos en Acción - ReDeA- y otras publicaciones especializadas

h) Seguimiento de las propuestas presentadas a través de proyectos de investigación y extensión universitaria

i) Informe periódico, devolución a las instituciones, actores comprometidos.

Brindaremos una explicación sucinta del estado de avance de las actividades mencionadas.

\section{Mesa de discusión y trabajo}

La mesa de discusión y trabajo se reunió por primera vez el 24/09/19 en la Secretaría de Relaciones Institucionales de la Facultad de Ciencias Jurídicas y Sociales donde se presentó el proyecto y programa a los integrantes de Grupo Promotor.

\section{Jornada "El Ministerio Público de la Provincia de Buenos} Aires. Perspectivas y nuevos desafios institucionales frente a la sociedad bonaerense"

03 de octubre de 2019. Edificio Karakachoff. UNLP.

Inicio. 16. Hs.

Palabras iniciales del Sr. Decano Miguel Berri.

Presentación de proyecto Cidercrit:Prof. Pablo Octavio Cabral y Dr. Alejandro Medici

Primer Panel. 16.30 hs.

I. Las experiencias no penales de otros Ministerios Públicos.

Coordina: Prof. Carolina Correge.

- Dra. Johana Cristallo. Procuración General de la Nación.

- Dr. Nelson Rapimán. Ministerio Púbico de la Defensa de Chubut 
- Dra. María José Rodríguez. Procuración de CABA.

- Dra. Inés Jaureguiberry. Fiscalía de Casación de la Provincia de Bs. As.

Segundo Panel 18 hs.

II. El Ministerio Público ante la Justicia Contencioso Administrativa.

Coordina: Prof. Irina Leal.

- Dr. Marcelo José Schreginger. Juez Contencioso Administrativo de la Cámara de San Nicolás.

- Dra. Analía Elíades. Prof. de Derecho Administrativo y Derecho a la Comunicación (UNLP)

- Dr. Luis Arias. Ex Juez en lo Contencioso Administrativo de La Plata.

- Dr. Mauro Benente. Profesor de la Universidad de José C. Paz.

Tercer Panel 19 hs.

III. El Ministerio Público bonaerense y los desafíos actuales. Coordina: Prof. Guillermo Rizi.

- Dr. Mario Coriolano. Defensor de Casación Penal de la Provincia de Bs. As.

- Dra. Daniela Bersi. Fiscal Adjunta del Ministerio Público provincial.

- Dr. Víctor Violini. Juez de Casación Penal de la Provincia de Bs. As.

- Dr. Guillermo Raúl Moreno. Prof. Historia Constitucional. Defensoría de Casación Penal de la Provincia de Bs As.

Palabras finales del Secretario de Relaciones Institucionales, Dr. Fernando Maitini.

\section{Conversatorio}

Se propone un conversatorio para dar cuenta de la experiencia llevada a cabo en la zona norte de la provincia de Buenos Aires, donde se generaron actividades en la defensa pública 
y en la justicia administrativa para promover el desarrollo de mecanismos eficaces de defensa oficial de DESCA.

Se propone la presencia de Damián Cebey (Juez de la Cámara Contencioso Administrativa de San Nicolás), Luciano Savignano (Juez contencioso Administrativo de Pergamino), Matías Sucunza (Funcionario del área planificación del Poder Judicial de la Provincia de Buenos Aires) y Gabriel Ganon (Ex defensor General del Departamento Judicial San Nicolás).

\section{Propuesta legislativa}

Uno de los objetivos iniciales de este programa es la modificación de la normativa estructural vigente del Ministerio Público de la provincia de Buenos Aires y la proposición de marcos regulatorios complementarios que motoricen los cometidos centrales del mismo.

\section{Propuesta de modificación constitucional por enmienda}

Teniendo en cuenta lo expresado, proponemos como un primer esbozo, la posible reforma al artículo 189 de la Constitución mediante el siguiente anteproyecto:

EL SENADO Y CÁMARA DE DIPUTADOS DE LA PROVINCIA DE BUENOS AIRES SANCIONAN CON FUERZA DE LEY

ARTÍCULO $1^{\circ}$ : Declaración de Necesidad. Declárase necesaria la reforma parcial de la Constitución de la Provincia de Buenos Aires.

ARTÍCULO $2^{\circ}$ : Objeto. Será objeto de reforma el artículo 189 de la Constitución de la Provincia de Buenos Aires, el que quedará redactado de la siguiente manera:

"Artículo 189: El ministerio Público es un órgano independiente con autonomía funcional y autarquía financiera que tiene por función promover la actuación de los órganos jurisdiccionales en defensa de la legalidad y de los intereses generales de la sociedad. Está integrado por el Procurador General y el 
Subprocurador General a cargo del Ministerio Público Fiscal; el Defensor General y Subdefensor General a cargo del Ministerio Público de la Defensa y demás miembros que establezca la ley.

Sus miembros gozan de inmunidades funcionales e intangibilidad de remuneraciones.

Los cargos de Defensor General y Subdefensor General serán designados y removidos de la misma forma y bajo los mismos procedimientos a los que esta Constitución contempló para los cargos de Procurador y Subprocurador General"

ARTÍCULO $3^{\circ}$ : Modalidad. Adóptase la modalidad de reforma por vía de Legislatura conforme lo contempla el artículo 206, inciso b) de la Constitución Provincial.

ARTÍCULO $4^{\circ}$ : Convocatoria. El Poder Ejecutivo convocará al electorado de la Provincia de Buenos Aires, a partir de la sanción de la presente Ley, a un plebiscito en la primera elección que se realice, para que se exprese en pro o en contra de la enmienda.

ARTÍCULO 5: Difusión. El Poder Ejecutivo dispondrá la amplia difusión del texto de la enmienda sujeto a plebiscito.

ARTÍCULO 6: Gastos y Recursos. Facúltase al Poder Ejecutivo a efectuar en el Presupuesto General de Gastos y Cálculo de Recursos correspondiente al ejercicio en el que se realice el plebiscito, previsto en el artículo $4^{\circ}$ de esta Ley, las adecuaciones necesarias para dar cumplimiento con el objeto de la presente.

ARTÍCULO $7^{\circ}$ : Comuníquese al Poder Ejecutivo.

\section{Bibliografía}

Abramovich, Víctor, Los estándares interamericanos de derechos humanos como marco para la formulación y el control de las politicas sociales, en ABRAMOVICH Víctor, BOVINO Alberto y COURTIS Christian, La aplicación de los Tratados sobre Derechos Humanos en el ámbito local. La experiencia de una década, Editores del Puerto SRL, Buenos Aires, 2007, ps. 217-253.

Abramovich, Víctor y Pautassi, Laura (Compiladores), La medición de derechos en las políticas sociales, Ediciones del Puerto, CABA, 2010. 
Azcune, Juan Ignacio, "El Ministerio Público de la defensa ante la justicia administrativa como garantía de los derechos económicos, sociales y culturales en la provincia de Buenos Aires", Revista La Ley, T.2015-B, p. 856-868.

Azcune, Juan Ignacio y Lafalce, Víctor; "Derecho administrativo $y$ grupos desventajados. Los servicios jurídicos gratuitos de asesoramiento y patrocinio", Infojus.

Andrieu, Mónica Graciela: "Las deudas jurídicas e institucionales de la Provincia de Buenos Aires: Establecimiento del Fuero Contencioso Administrativo y el Ministerio Público", Revista de Derecho Público, 2003-2, p. 323.

Benente, Mauro (Coordinador), "Los derechos económicos, sociales y culturales en los tribunales superiores de provincia", Edunpaz y Editores del Sur, José C. Paz, 2018.

CEJA, Angela Ledesma, "El rol del Ministerio Público en casos no penales en América Latina", Santiago de Chile, 2019.

Chayes, Abram, El rol del juez en el litigio de interés público, Traducción al español de Olivia MINATTA y Francisco VERBIC, en Revista de Processo No 268 -junho 2017-.

De Césaris, Juan, Ministerio Público Fiscal y de la Defensa, Silva Palacio de Caeiro (Dirección), La Ley, Buenos Aires, 2012.

Haberle, Peter, Los derechos fundamentales en el Estado prestacional. Editorial Palestra, Lima, 2019.

López, José Ignacio y Cabral, Pablo Octavio (2016) "La declaración de inconstitucionalidad de la Ley de Ingreso Irrestricto a las Universidades Públicas. Una interpretación contraria al Derecho Internacional de los Derechos Humanos", Revista La Ley, disponible en SEDICI; http://hdl.handle.net/10915/61425, 2016.

Medici, A., Articulación de docencia-investigación extensión para una práctica pedagógica crítica en la enseñanza de los Derechos Humanos, Derechos En Acción, 7, https://doi. org/10.24215/25251678e147, 2018.

Moreno, Guillermo Raúl, Comentarios a la Constitución de la Provincia de Buenos Aires. Concordada y con notas de jurisprudencia, Librería Editora Platense, La Plata, 2019.

Savignano, Luciano, "El Ministerio Público Fiscal de la Provincia de Buenos Aires ante el Fuero Contencioso Administrativo y 
de ejecuciones Tributarias. Una Propuesta", Revista RAP Bs. As. (73/74), pág. 163 y siguientes.

Sagastizabal, Maria Ángeles y Perlo, Claudia (2002),La investigación-acción como estrategia de cambio de las organizaciones, Editorial Stella-La Crujía.

Sucunza, Matías A., El derecho constitucional-convencional al debido proceso colectivo: conceptualización e interpelaciones en pos de su efectividad, en Revista de Derecho Público, Santa Fe, RubinzalCulzoni, 2016-I, pp. 105-163.

Sucunza, Matías, La indivisibilidad e interdependencia en derechos humanos: conceptualización e interpelaciones en pos de su concreción; MJ-DOC-6787 y 6788 AR, 10 y 11 de julio de 2014.

Sucunza, Matías, Pobreza y proyecto de vida: ni libertad ni igualdad. ¿Los derechos humanos como qué?, MJ-DOC-7334-AR.

Verbic, Francisco, Tutela Colectiva de derechos en Argentina. Evolución bistórica, legitimación activa, ámbito de aplicación y tres cuestiones prácticas fundamentales para su efectiva vigencia, 2012-05, RDP número especial, Conferencia IAPL-IIDP.

Verbic, Francisco, La Corte Suprema Argentina y la construcción del derecho constitucional a un debido proceso colectivo, Int'lJournal of Procedural Law, Volumen 5 -2015-, $\mathrm{N}^{\mathrm{o}} 1$. 